\title{
Patient Size-Dependent Dosimetry Methodology Applied to 18F-FDG Using New ICRP Mesh Phantoms
}

Running title: Patient-dependent FDG dosimetry

Authors: Lukas M. Carter', Chansoo Choi², Simone Krebs³, Bradley J. Beattiel, Chan Hyeong Kim², Heiko Schoder³, Wesley E. Bolch4, Adam L. Kesner ${ }^{1}$

\section{Affiliations:}

'Department of Medical Physics, Memorial Sloan Kettering Cancer Center, New York, NY, USA

2Department of Nuclear Engineering, Hanyang University, Seoul, Republic of Korea 3Department of Radiology, Memorial Sloan Kettering Cancer Center, New York, NY, USA

4J. Crayton Pruitt Department of Biomedical Engineering, University of Florida, Gainesville, $\mathrm{FL}$, USA

\section{Correspondence:}

Lukas M. Carter

Department of Medical Physics, MSKCC

1250 1st Avenue, New York, NY, 10065, USA

carterl1@mskcc.org

ORCiD: https://orcid.org/0000-0003-4848-4190

Keywords: FDG; patient-dependent dosimetry, PARaDIM, PHITS, phantom 


\begin{abstract}
Despite the known influence of anatomic variability on internal dosimetry, dosimetry for ${ }^{18} \mathrm{~F}-\mathrm{FDG}$ and other diagnostic radiopharmaceuticals is routinely derived using reference phantoms, which embody population-averaged morphometry for a given age and sex. Moreover, phantom format affects dosimetry estimates to varying extent. Here, we applied newly developed mesh format reference phantoms and a patient-dependent phantom library to assess the impact of height, weight, and body contour variation on dosimetry of $18 \mathrm{~F}-F D G$. We compared the mesh reference phantom dosimetry estimates with corresponding estimates from common software to identify differences related to phantom format or software implementation. Our study serves as an example of how more precise patient size-dependent dosimetry methodology could be performed.
\end{abstract}

Methods: Absorbed dose coefficients were computed for the adult mesh reference phantoms and derivative patient-dependent phantom series by Monte Carlo simulation using the PHITS radiation transport code within PARaDIM software. The dose coefficients were compared with reference absorbed dose coefficients obtained from ICRP Publication 128, or generated using software including OLINDA 2.1, OLINDA 1.1, and IDAC-dose 2.1.

Results: Differences in dosimetry arising from anatomical variations were shown to be significant, with detriment-weighted dose coefficients for the percentile-specific phantoms varying by up to $\pm 40 \%$ relative to the corresponding reference phantom effective dose coefficients, irrespective of phantom format. Similar variations were seen in the individual organ absorbed dose coefficients for the percentile-specific phantoms relative to the reference phantoms. The effective dose coefficient for the mesh reference adult was $0.017 \mathrm{mSv} / \mathrm{MBq}$, which was $5 \%$ higher than estimated by a corresponding voxel phantom, and $10 \%$ lower than estimated by the stylized phantom format.

Conclusions: We observed notable variability in 18F-FDG dosimetry across morphometrically different patients, supporting the use of patient-dependent phantoms for more accurate dosimetric estimations relative to standard reference dosimetry. These data may help in optimizing imaging protocols and research studies, in particular when longer-lived isotopes are employed. 


\section{INTRODUCTION}

2-Deoxy-2-[18F]fluoroglucose (18F-FDG) is the most widely used diagnostic radiopharmaceutical in oncology, with 2.2 million clinical PET scans performed across U.S. facilities in 2019(1). The typical effective dose from 18F-FDG imaging is $\sim 10 \mathrm{mSV}$ and is considered low $(2,3)$. Nevertheless, the increasing use of radiation-based medical imaging over the past several decades has led to concerns about possible detriment, which have precipitated campaigns such as Image Wisely (adult patients) and Image Gently (pediatric patients)(4,5). A cornerstone of those campaigns is attention to optimization. Accurate dosimetry is fundamental to understanding relationships between radiation dose and patient detriment and is needed to provide objective recommendations for administered activity for different patient populations(6).

Dosimetry estimates in nuclear medicine are derived using Monte Carlo-based dose calculations incorporating computerized representations of anatomy known as computational phantoms. The accuracy of these estimates depends on the degree to which anatomical features of the patient are modelled within the phantom. Virtually all routine dosimetry estimates for ${ }^{18} \mathrm{~F}-\mathrm{FDG}$ in adult patients have utilized standard reference (i.e. non patient-specific) phantoms to represent patient anatomy. Reference phantoms serve to define an "average patient" based on only age and sex criteria; they do not consider differing body sizes and organ dimensions, which may influence absorbed dose calculations by $20-60 \%(7)$. The geometric format (e.g. mesh, voxel, stylized, or hybrid) used to define the phantom anatomy further influences dose calculations. Despite the availability of more modern formats, stylized adult phantoms $(8,9)$ as described in ICRP 23(10) continue to be routinely used in nuclear medicine dosimetry software, and provide the underpinning for dose coefficients promulgated in current accepted sources of radiopharmaceutical reference data(11). Limitations of stylized phantoms include reliance on simple linear and quadratic surface equations, which coarsely approximate human anatomy and generally underestimate organ cross-dose contributions for low energy photons. Progress in computational phantom and Monte Carlo code development (12-19) now enable more accurate dosimetry protocols, which will support dosimetry research, optimization of clinical imaging protocols, and planning of research studies.

The ICRP recently developed mesh format reference computational phantoms (MRCPs) for the adult male and female, which provide anatomically more realistic representations of the human body (Figure 1) (20). For example, these phantoms define numerous additional source and target regions, and define small, thin, or complex radiosensitive target regions impractical to treat using voxel or stylized phantom formats. More recently, the adult mesh reference phantoms were re-shaped and scaled to match Caucasian patient population-dependent parameters extracted from anthropometric survey data $(21,22)$ - culminating in an additional 9 male and 9 female phantoms representing the $10^{\text {th }}, 50^{\text {th }}$, and $90^{\text {th }}$ percentiles of standing height and weight for the adult Caucasian population. Termed the "percentile-specific" phantom series, these 18 phantoms are morphometrically considered patient-dependent phantoms and foster 
research into dosimetric implications of adult patient size variability across population subsets.(23)

A primary objective of this work was to assess differences in ${ }^{18 F-F D G ~ d o s e ~}$ coefficient estimations using a patient-dependent dosimetry paradigm, in comparison to standard "one-size-fits-all" reference dosimetry. We therefore calculated dosimetry estimates across a series of current-generation mesh patient dependent phantoms to evaluate the differences arising from anatomical variability. We also investigated differences due to phantom format by comparing dose coefficients derived using the mesh reference phantoms with those obtained using stylized reference phantoms, voxel reference phantoms, or hybrid reference phantoms.

\section{MATERIALS AND METHODS}

\section{Biokinetic Data for ${ }^{18 F-F D G}$}

Biokinetic data for ${ }^{18}$ F-FDG, in the form of time-integrated activity coefficients (TIACs) (24) for the brain, heart wall, lungs, liver, urinary bladder contents, and rest of body, were obtained from the ICRP 128(11) radiopharmaceutical data compendium (Table 1). The TIAC for the lung region provided in ICRP 128 applies to both lungs jointly; however, in the mesh phantoms, the lungs are modeled as separate regions, with each requiring an input TIAC. Therefore, the lung TIAC was divided between the right and left lung regions by mass fraction (relative to the total lung mass). Similarly, the rest of body TIAC was divided among its comprising regions by tissue mass fraction (relative to the total tissue mass of the rest of body).

\section{Absorbed Dose Dalculations with Reference and Patient-Dependent Mesh Phantoms}

Absorbed dose coefficients (in units of mGy/MBq administered activity) for the explicitly defined mesh reference and percentile-specific phantom regions were computed by direct Monte Carlo simulation using the PHITS-based(15) PARaDIM software (18). Each simulation was configured using the "multi-source" absorbed dose mode of PARaDIM, which generates both region-level mean absorbed dose coefficients as well as a 3D voxelized dose map (here, sampled at $1.0 \mathrm{~cm}$ isotropic spatial resolution). The material surrounding the phantom was defined as void. A total of $10^{7}$ histories were simulated for each phantom. PARaDIM defaults for physical models were used, which specified the PHITS-EGS5 method for treatment of multiple scattering, explicit treatment of fluorescent $x$-rays, consideration of Rayleigh and incoherent scattering, and consideration of electron-impact ionization. Sampling was utilized for determination of bremsstrahlung polar angles, pair electron polar angles, and distribution of photoelectrons. Cutoff energies of $1.0 \mathrm{keV}$ were utilized for both positrons and photons.

The ICRP defines several target regions that comprise multiple uniquely defined target regions within the phantoms (e.g. lungs, comprising left and right lung; kidneys, 
comprising left and right renal pelvis, cortex, and medulla). The mean dose to such regions was computed as a mass-weighted combination of absorbed doses to each subregion:

$d_{\text {mreg }}=\sum_{r_{T} \in \text { mreg }} \frac{M\left(r_{T} \in \text { mreg }\right)}{M(\text { mreg })} d\left(r_{T} \in\right.$ mreg $)$

Eqn. 1

where $d_{\text {mreg }}$ is the absorbed dose coefficient for a multi-region target mreg; $M\left(r_{T} \in \operatorname{mreg}\right)$ is the mass of a region $r_{T}$ comprising the multi-region target; $M(\mathrm{mreg})$ is the total mass of the multi-region target; and $d\left(r_{T} \in \mathrm{mreg}\right)$ is the absorbed dose coefficient for a subregion.

The active marrow and endosteum are implicitly defined within the spongiosa and marrow cavity regions of the mesh reference and percentile-specific phantoms; the absorbed dose coefficients for these specific tissues was derived from those for the corresponding spongiosa and marrow cavities per the recommendations in ICRP 116, viz:

$d_{\text {skel }}(A M)=\sum_{r_{T} \in \text { skel }} \frac{M\left(A M, r_{T} \in \text { skel }\right)}{M(A M)} d\left(S P, r_{T} \in\right.$ skel $)$

Eqn. 2

$d_{\text {skel }}(E C)=\sum_{r_{T} \in \text { skel }} \frac{M\left(E C, r_{T} \in \text { skel }\right)}{M(E C)} d\left(S P, r_{T} \in\right.$ skel $)+\sum_{r_{T}} \frac{M\left(E C, r_{T} \in \text { skel }\right)}{M(E C)} d\left(M M, r_{T} \in\right.$ skel $) \quad$ Eqn. 3

where $d_{\text {skel }}(A M)$ and $d_{\text {skel }}(E C)$ are the skeletal-averaged absorbed dose coefficients for the active marrow and endosteal cells, respectively; $M\left(A M, r_{T} \in\right.$ skel $)$ and $M\left(E C, r_{T} \in\right.$ skel $)$ are the masses of these tissues in skeletal target region $r_{T} \in \operatorname{skel} ; M(A M)$ and $M(E C)$ are the total masses of active marrow and endosteal cells contained within the entire skeleton; and $d\left(S P, r_{T} \in\right.$ skel $)$ and $d\left(M M, r_{T} \in\right.$ skel $)$ are the absorbed dose coefficients for the spongiosa and medullary marrow regions which encompass the active marrow and endosteal cells in skeletal region $r_{T}$.

The effective dose quantity is derived from absorbed dose calculations and is a widely used concept in diagnostic radiation dosimetry - is provides a strategy for combining the variable organ doses into a single stochastic risk-relevant number(25,26,27). Effective dose coefficients(28) were computed using the methodology and tissue-specific weighting factors promulgated in ICRP 103 and ICRP 133, viz:

$e=\sum_{T} w_{T} \sum_{R} w_{R}\left[\frac{d_{T, R}^{\text {male }}+d_{T, R}^{\text {female }}}{2}\right]$

Eqn. 4

where $e$ is the effective dose coefficient, $w_{T}$ is the tissue-specific weighting factor for tissue $T$, and $w_{R}$ is the radiation weighting factor for radiation type $R$ (here, taken as unity for $18 \mathrm{~F}$ positrons and photons).

By definition, the effective dose is relevant only for the reference person (i.e. it does not formally apply to height, weight or otherwise constrained subsets of the patient population) $(24,25)$. It is also restricted to the use of sex-averaged organ absorbed doses as per Eqn. 4. To gain insight into an similar single-value risk characterization, a related quantity, the detriment weighted dose (29-31) has been previously introduced which applies ICRP tissue and radiation weighting factors, but removes the requirement of sex- 
averaging of organ absorbed doses, as well as the restriction of non-reference phantom dose values. The detriment-weighted dose provides a basis for consideration of risk from stochastic effects of radiation, as relevant to population subsets (as used here) or potentially individuals, and is used with the justification that absorbed dose, not patient geometry, is the relevant seat for quantifying risk:

$e_{D W}^{S, H, M}=\sum_{T} w_{T} \sum_{R} w_{R} d_{T, R}^{S, H, M}$

Eqn. 5

where $e_{D W}^{S, H, M}$ is the detriment-weighted dose coefficient for a phantom of sex $S$, height $H$, and total body mass $M$.

\section{Absorbed Dose Calculations with Reference Voxel, Stylized, and Hybrid Phantoms}

The "ICRP 89 adult" male and female hybrid reference phantoms(19) were utilized in OLINDA 2.1. The adult male and female stylized reference phantoms were utilized in OLINDA 1.1, and the ICRP 110 adult voxel reference phantoms were used in IDAC-dose 2.1 software. The default organ masses were used for each phantom in all software. For further details on the phantoms used, please refer to Table 2.

\section{Hardware and Software Specification}

An HP Z8 workstation running Microsoft Windows 10 operating system and utilizing a 3.6-GHz Intel Xeon 5122 processor, was used for all Monte Carlo calculations.

3D Slicer (version 4.11; www.slicer.org) was used for dose map visualization, and Paraview (version 5.6.2; www.paraview.org) was used for 3D rendering of phantom geometry. Statistical analysis was performed with GraphPad Prism (version 8.3.1; GraphPad Software, Inc.).

\section{RESULTS}

Figure 2 shows voxel-level absorbed dose coefficients for the mesh reference and percentile-specific phantom series. These 3D dose maps are volume-rendered as maximum intensity projections, and as they were derived under the assumption of uniformly distributed activity within whole organs, they are intended to reflect spatial nonuniformity of dose deposition averaged across a patient subpopulation matching the specified height and weight. Region-level mean absorbed dose coefficients for selected target organs of the phantoms are presented in Figure 3 and Figure 4. A comprehensive list of dose coefficients for all defined target regions is provided in Supplemental Tables S1-8. The highest absorbed dose coefficients were observed in the heart wall, followed by the urinary bladder wall, and brain, for the male and female mesh phantoms and their voxel analogs implemented in IDAC-dose 2.1 (Figure 5). In contrast, the urinary bladder wall was identified as the critical organ in the stylized and hybrid reference phantom 
dose estimates, with the bladder wall absorbed dose coefficients being approximately two-fold higher than those for the heart wall (the next most-irradiated tissue), and were approximately 2.5 -fold higher than estimated with the mesh reference phantoms. This discrepancy has been noted previously (18), and here, was the largest relative deviation in the dose coefficient estimated by the mesh reference phantoms in comparison to the corresponding stylized and hybrid phantom estimates. The disagreement can be partially explained by the methodology employed for determination of specific absorbed fractions used in derivation of self-irradiation S-values (and correspondingly, absorbed dose coefficients) for the urinary bladder of the stylized phantoms $(32,33)$. Absorbed dose coefficients for the basal cell layer of the urinary bladder of the mesh reference adults $(0.089 \mathrm{mGy} / \mathrm{MBq}$ and $0.091 \mathrm{mGy} / \mathrm{MBq}$ for adult male and female, respectively; Supplemental Table S1-2) were more consistent with the stylized and hybrid phantom bladder dose estimates.

Relative to the reference mesh phantoms of the corresponding sex, absorbed dose coefficients for most target organs of the percentile-specific phantom series deviated by $20-30 \%$ for the $10^{\text {th }}$ and $90^{\text {th }}$ weight percentile extremes. The reference and percentile-specific estimates converged near the H50 / W50 percentile classification; this was expected due to the similar body morphometry of the reference phantoms (176.0 $\mathrm{cm} / 73 \mathrm{~kg}$ male; $163 \mathrm{~cm} / 60.0 \mathrm{~kg}$ female) and the H50 / W50 analogs (176.5 cm / 79.3 $\mathrm{kg}$ male; $163.3 \mathrm{~cm} / 64.1 \mathrm{~kg}$ female). Of all target tissues, absorbed dose coefficients for the brain varied the least (in relative terms) among phantoms of the same sex, primarily due to the weak dependence of brain mass on body morphometry - particularly body mass for a given height.

The effective dose coefficient was calculated as $0.017 \mathrm{mSv} / \mathrm{MBq}$, using the male and female mesh reference phantoms in combination with the tissue-specific weighting factors of ICRP 103. This represents a 10\% decrease relative to ICRP 128 estimate of 0.019 $\mathrm{mSv} / \mathrm{MBq}$ and reflects geometric differences in the phantoms, tissue-specific weighting factors (Table 2), and lack of sex-averaging the ICRP 128 organ doses used to derive the effective dose. The effective dose coefficient for the ICRP 110 voxel phantoms was 0.016 $\mathrm{mSv} / \mathrm{MBq}$ (sex-averaged) which agrees within $\sim 5 \%$ with the mesh reference phantom estimates; of note, these phantoms were designed to represent identical geometry, but in different formats.

The detriment-weighted dose coefficient for each of the percentile-specific phantoms was computed by applying ICRP 103 tissue-specific weighting factors directly to the associated tissue equivalent dose coefficients (i.e. not using reference male/female equivalent dose averaging; see Eqn. 5). The patient-dependence of the detriment-weighted dose is provided in Figure 6 for the percentile-specific phantoms. Though the relationships depend on height, weight, sex, and underlying physical factors (linear energy transfer, attenuation), the detriment-weighted dose is strongly negatively correlated with body mass (Spearman's $r=-0.9505 ; p<0.0001$ ), but less strongly with BMI (Spearman's $r=-0.7049 ; p=0.0011)$. Notably, given a particular sex, the detrimentweighted dose vs. mass curves for different height classifications were observed to 
decrease monotonically. For a given mass, detriment-weighted dose coefficients for females were larger than for males. Together these results suggest that consideration of body morphometry, rather than only body mass, will further improve dose estimates and optimization strategies.

\section{DISCUSSION}

Diagnostic dose measurement has roles in optimization, comparing techniques and modalities, quality assurance, research and development, and support of regulatory standards and public health protection.(25) Understanding the variability and uncertainty in dose estimates is of heightened importance considering repeat oncologic imaging sessions where uncertainties must be propagated across multiple imaging sessions throughout disease management. The contributing factors for uncertainty in organ-level absorbed dose calculations (34-36) can include uncertainty in: 1) radionuclide physical decay data, 2) system calibration, 3) Monte Carlo calculation of energy deposition, 4) body morphometry of the patient in comparison to the phantom representing the patient, 5) radiopharmaceutical biokinetics and intra-organ distribution. Of these, the uncertainty in radionuclide decay data is negligible in most cases, and uncertainty in Monte Carlo simulations can be minimized with adequate sampling. In contrast, body morphometry and radiopharmaceutical biokinetics and intra-organ distribution represent the principal organ-level dosimetric uncertainties.

Our study addresses uncertainty and variability in body morphometry for specific subsets of the Caucasian patient population, and we provide patient-dependent dose estimates (with a broad approximation of the anatomy of height-and weight-defined subsets of the patient population), in contrast to patient-specific calculations (which account for the unique anatomy of a specific patient) (23). In doing so, we have utilized reference ${ }^{18} \mathrm{~F}-\mathrm{FDG}$ biokinetic data in order to ensure the variability in the results originates plainly from the underlying anatomical differences. The biokinetics of 18F-FDG may vary across patients, for instance due to dietary conditions, presence of tumors, and kidney dysfunction. To our knowledge, the biokinetic dependence on adult body morphometry has not been comprehensively investigated. Considering the uncertainty in biokinetics, as well as the impracticality of creating patient-specific phantoms for routine imaging procedures, there is some rationale for applying these dose estimates to specific patients by matching them to the appropriate height and weight percentiles. Such strategies could support scan-specific dose reporting in nuclear medicine in the near future.

\section{Role of Patient-Dependent Dose Coefficients in Diagnostic Nuclear Medicine}

Optimization strategies for FDG should continue to prioritize the delivery of diagnostic quality images. The Image Wisely and Image Gently initiatives $(4,5)$ espouse safe and efficacious imaging by striving to deliver diagnostic quality images while maintaining radiation doses as low as reasonably achievable. Our calculations provide 
supporting data for patient size-based 18F-FDG administration and related optimization strategies. At ${ }^{18 F-F D G}$ dose levels expected clinically, the confidence intervals in risk-dose relationships are currently too broad to justify the consideration of risk in management of individual patients $(37,38)$. Therefore, the dose coefficients we have provided should be used primarily for improved scan-specific dose reporting, which will enable better elucidation of dose-risk relationships in epidemiologic studies. Incorporating patient sizedependent variation in 18 F-FDG biokinetics would allow further refinement of the present dose coefficient estimates and would allow them to be more confidently used in setting guidelines for administered activity as a function of adult body morphometry. A greater impact of morphometry-dependent variation in absorbed dose and detriment-weighted dose coefficients can be expected with longer half-life diagnostic radiopharmaceuticals.

\section{Methodological Considerations}

In contrast with the orthodox method of computing dose coefficients from specific absorbed fraction-derived S-value lookup tables, here, we have computed task-specific dose coefficients via direct Monte Carlo simulation. The derivation of a complete set of phantom organ specific absorbed fractions requires a monumental computational effort. For example, ICRP 133 provides specific absorbed fractions for the ICRP 110-series adult phantoms, for 79 unique source regions, across three corpuscular radiation types plus photons, and $\sim 20$ discrete energies necessary for interpolation - effectively requiring over 6,000 individual Monte Carlo simulations per phantom - but thereafter enabling dose from any radionuclide/biokinetic dataset to be immediately computed. For the direct approach used here, a single phantom requires a new Monte Carlo simulation for every biokinetic dataset, but the simulation can be run on a standard desktop computer on a clinically acceptable timescale. Thus, future availability of specific absorbed fractions for the mesh reference and percentile specific phantoms will increase flexibility and computation speed, but their current unavailability should not present a barrier to implementation of these phantoms.

Some organ-level dosimetry software, including OLINDA, allow users to modify reference phantom organ masses to approximate patient-specific dose calculations. These approaches typically involve linearly scaling the self-S contributions from weakly penetrating radiations (alpha particles and electrons) with inverse mass, while photon self-S contributions are scaled inversely with the $2 / 3$ power of the mass(33). This approach assumes that source-target proximity is invariant upon changes in organ mass or patient shape. This approach is reasonable when the phantom already recapitulates the salient morphometry of the patient or patient population subset (e.g. for small mass variation in larger spheriform organs), but may be subject to considerable errors when, for example, scaling reference phantom S-values to match patients of much smaller or much larger overall size. As the percentile-specific phantoms account for gross size variation across patients, they would serve as a better basis for patient-specific organ S-value scaling. 


\section{CONCLUSION}

Using newly developed computational phantoms, we provide patientdependent dose coefficients and revised reference dose coefficients for 18F-FDG. Of note, differences in patient morphometry imparted large deviations in dose coefficients for the upper and lower $10^{\text {th }}$ percentile extremes of patient height and weight (up to \pm $40 \%$ relative to the reference patient). While our work was limited to 18 F-FDG, greater impact is expected for longer-lived isotopes in imaging. These data pertain to stochastic risk estimates and should not be used for individual patient management, but the methodology described may support optimization of administered activities in clinical practice.

\section{ACKNOWLEDGEMENTS}

This research was funded in part through the $\mathrm{NIH} / \mathrm{NCl}$ Cancer Center Support Grant P30 CA008748 and NIH U01 EB028234. L.M.C acknowledges support from the Ruth L. Kirschstein NRSA Postdoctoral Fellowship (NIH F32 EB025050). S.K. was supported in part by the $\mathrm{NIH} / \mathrm{NCl}$ Paul Calabresi Career Development Award for Clinical Oncology (K12 CA 184746). We are enormously grateful for technical support from the PHITS team of the Japanese Atomic Energy Administration, including Dr. Tatsuhiko Sato and Dr. Takuya Furuta. No other potential conflict of interest relevant to this article was reported.

\section{KEY POINTS}

Question: Can the influence of patient size on 18F-FDG dosimetry be elucidated using newly-developed patient-dependent phantoms?

Pertinent findings: Dose coefficients for ${ }^{18}$ F-FDG were shown to vary by up to $\pm 40 \%$ across the $10^{\text {th }}-90^{\text {th }}$ percentiles for standing height and weight across the Caucasian adult patient population.

Implications for patient care: Implementation of the current state-of-the-art phantom libraries into modernized dosimetry software will foster greater accuracy in dosimetry and ultimately support optimized strategies for personalized nuclear medicine. 


\section{REFERENCES}

1. 2020 PET imaging market summary report. Int Mark Ventur. 2020.

2. Council NR, Studies $D$ on $E$ and $L$, Research $B$ on RE, Radiation $C$ to AHR from $E$ to $L L$ of I. Health risks from exposure to low levels of ionizing radiation: BEIR VII Phase 2. National Academies Press; 2006.

3. Vetter RJ. ICRP Publication 103, The recommendations of the international commission on radiological protection. Health Phys. 2008;95:445.

4. Brink JA, Amis ES. Image Wisely: A Campaign to increase awareness about adult radiation protection. Radiology. 2010;257:601-602.

5. Applegate KE, Cost NG. Image Gently: A campaign to reduce children's and adolescents' risk for cancer during adulthood. J Adolesc Health. 2013;52:S93-S97.

6. Sgouros G, Frey EC, Bolch WE, Wayson MB, Abadia AF, Treves ST. An approach for balancing diagnostic image quality with cancer risk: application to pediatric diagnostic imaging of 99mTc-dimercaptosuccinic acid. J Nucl Med. 2011;52:19231929.

7. Mattsson S, Johansson L, Leide Svegborn S, et al. Radiation dose to patients from radiopharmaceuticals: a compendium of current information related to frequently used substances. Ann ICRP. 2015;44:7-321.

8. Cristy M, Eckerman KF. Specific absorbed fractions of energy at various ages from internal photon sources: 7, Adult male. Oak Ridge National Lab.; 1987.

9. Snyder WS, Fisher HL, Ford MR, Warner GG. Estimates of absorbed fractions for monoenergetic photon sources uniformly distributed in various organs of a heterogeneous phantom. J Nucl Med Off Publ Soc Nucl Med. August 1969:Suppl 3:752.

10. ICRP Publication 23. SAGE Publ Ltd. October 2020.

11. Mattsson S, Johansson L, Leide Svegborn S, et al. Radiation dose to patients from radiopharmaceuticals: a compendium of current information related to frequently used substances. Ann ICRP. 2015;44:7-321.

12. Zubal IG, Harrell CR, Smith EO, Rattner Z, Gindi G, Hoffer PB. Computerized threedimensional segmented human anatomy. Med Phys. 1994;21:299-302.

13. Zaidi $H, X \cup X G$. Computational anthropomorphic models of the human anatomy: the path to realistic Monte Carlo modeling in radiological sciences. Annu Rev Biomed Eng. 2007:9:471-500.

14. Geyer AM, O'Reilly S, Lee C, Long DJ, Bolch WE. The UF/NCl family of hybrid computational phantoms representing the current US population of male and female 
children, adolescents, and adults-application to CT dosimetry. Phys Med Biol. 2014;59:5225-5242.

15. Sato T, Iwamoto Y, Hashimoto S, et al. Features of Particle and Heavy Ion Transport code System (PHITS) version 3.02. J Nucl Sci Technol. 2018;55:684-690.

16. Furuta T, Sato T, Han MC, et al. Implementation of tetrahedral-mesh geometry in Monte Carlo radiation transport code PHITS. Phys Med Biol. 2017;62:4798.

17. Agostinelli S, Allison J, Amako K, et al. Geant4-a simulation toolkit. Nucl Instrum Methods Phys Res Sect Accel Spectrometers Detect Assoc Equip. 2003;506:250-303.

18. Carter LM, Crawford TM, Sato T, et al. PARaDIM - A PHITS-based Monte Carlo tool for internal dosimetry with tetrahedral mesh computational phantoms. J Nucl Med. June 2019:jnumed.119.229013.

19. Stabin MG, XU XG, Emmons MA, Segars WP, Shi C, Fernald MJ. RADAR reference adult, pediatric, and pregnant female phantom series for internal and external dosimetry. $J$ Nucl Med. 2012;53:1807-1813.

20. Kim CH, Yeom YS, Petoussi-Henss N, et al. ICRP Publication 145: Adult mesh-type reference computational phantoms. Ann ICRP. 2020;49:13-201.

21. Cassola VF, Milian FM, Kramer R, Lira CAB de O, Khoury HJ. Standing adult human phantoms based on 10th, 50th and 90th mass and height percentiles of male and female Caucasian populations. Phys Med Biol. 2011;56:3749-3772.

22. Lee H, Yeom YS, Nguyen TT, et al. Percentile-specific computational phantoms constructed from ICRP mesh-type reference computational phantoms (MRCPs). Phys Med Biol. January 2019.

23. Bolch W, Lee C, Wayson M, Johnson P. Hybrid computational phantoms for medical dose reconstruction. Radiat Environ Biophys. 2010;49:155-168.

24. Bolch WE, Eckerman KF, Sgouros G, Thomas SR. MIRD pamphlet No. 21: a generalized schema for radiopharmaceutical dosimetry--standardization of nomenclature. J NuCl Med Off Publ Soc Nucl Med. 2009;50:477-484.

25. Martin CJ, Harrison JD, Rehani MM. Effective dose from radiation exposure in medicine: Past, present, and future. Phys Med. 2020;79:87-92.

26. Harrison JD, Balonov M, Bochud F, et al. ICRP Publication 147: Use of dose quantities in radiological protection. Ann ICRP. 2021;50:9-82.

27. Harrison JD, Balonov MI, Bochud FO, et al. The use of dose quantities in radiological protection: ICRP Publication 147 Ann ICRP 50(1) 2021. J Radiol Prot. 2021. 
28. Bolch WE, Jokisch D, Zankl M, et al. ICRP Publication 133: The ICRP computational framework for internal dose assessment for reference adults: specific absorbed fractions. Ann ICRP. 2016;45:5-73.

29. Kofler C, Domal S, Satoh D, Dewji S, Eckerman K, Bolch WE. Organ and detrimentweighted dose rate coefficients for exposure to radionuclide-contaminated soil considering body morphometries that differ from reference conditions: adults and children. Radiat Environ Biophys. 2019;58:477-492.

30. Brown J, Sexton-Stallone B, Li Y, et al. Body morphometry appropriate computational phantoms for dose and risk optimization in pediatric renal imaging with Tc-99m DMSA and Tc-99m MAG3. Phys Med Biol. 2020.

31. Brown J, Sexton-Stallone B, Li Y, et al. Dosimetric considerations of TC-99m MDP uptake within the epiphyseal plates of the long bones of pediatric patients. Phys Med Biol. 2020.

32. Stabin MG. MIRDOSE: Personal computer software for internal dose assessment in nuclear medicine. J Nucl Med. 1996;37:538-546.

33. Stabin MG, Sparks RB, Crowe E. OLINDA/EXM: the second-generation personal computer software for internal dose assessment in nuclear medicine. J Nucl Med. 2005;46:1023-1027.

34. Stabin MG. Uncertainties in internal dose calculations for radiopharmaceuticals. j nucl med. 2008;49:853-860.

35. Gear Jl, Cox MG, Gustafsson J, et al. EANM practical guidance on uncertainty analysis for molecular radiotherapy absorbed dose calculations. Eur I Nucl Med Mol Imaging. 2018;45:2456-2474.

36. Zvereva A, Kamp F, Schlattl H, Zankl M, Parodi K. Impact of interpatient variability on organ dose estimates according to MIRD schema: Uncertainty and variance-based sensitivity analysis. Med Phys. 2018;45:3391-3403.

37. Weber W, Zanzonico P. The controversial linear no-threshold model. J NuCl Med. 2017:58:7-8.

38. Siegel JA, Pennington CW, Sacks B. Subjecting radiologic imaging to the linear nothreshold hypothesis: a non sequitur of non-trivial proportion. J Nucl Med. 2017;58:1-6.

39. Stabin MG, Emmons MA, Segars WP, Fernald MJ. Realistic reference adult and paediatric phantom series for internal and external dosimetry. Radiat Prot Dosimetry. 2012;149:56-59.

40. Menzel H-G, Clement C, DeLuca P. ICRP Publication 110. Realistic reference phantoms: an icrp/icru joint effort. a report of adult reference computational phantoms. Ann ICRP. 2009;39:1-164. 
41. Andersson M, Johansson L, Eckerman K, Mattsson S. IDAC-Dose 2.1, an internal dosimetry program for diagnostic nuclear medicine based on the ICRP adult reference voxel phantoms. EJNMMI Res. 2017;7:88. 


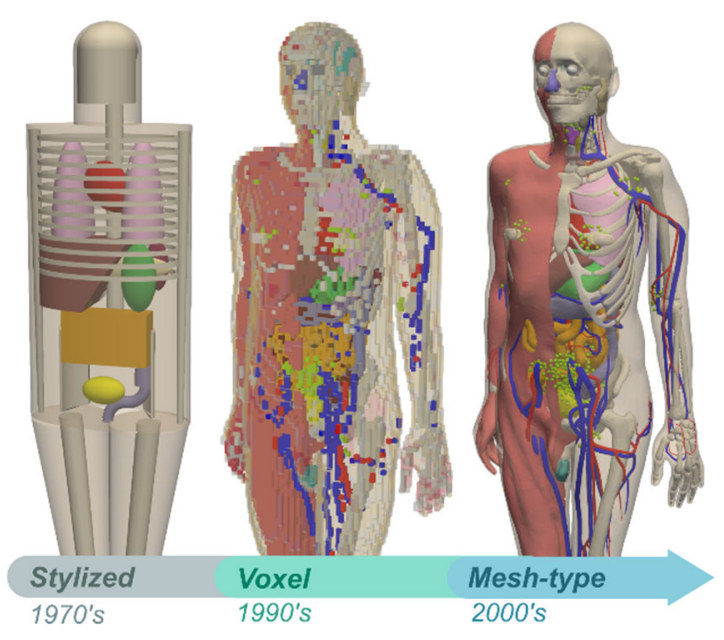

Figure 1: Comparison of phantom formats. Left: MIRD 5 era stylized adult anthropomorphic phantom (1969; 25 source/target organs) used in OLINDA 1.0 and ICRP 128. Middle: ICRP 110 adult male voxel phantom (2009; 79 source regions, 43 target regions) used in IDAC-dose 2.1. Right: ICRP mesh reference adult male (2020; 190 source regions, 153 target regions) archetypal example used in this work. 

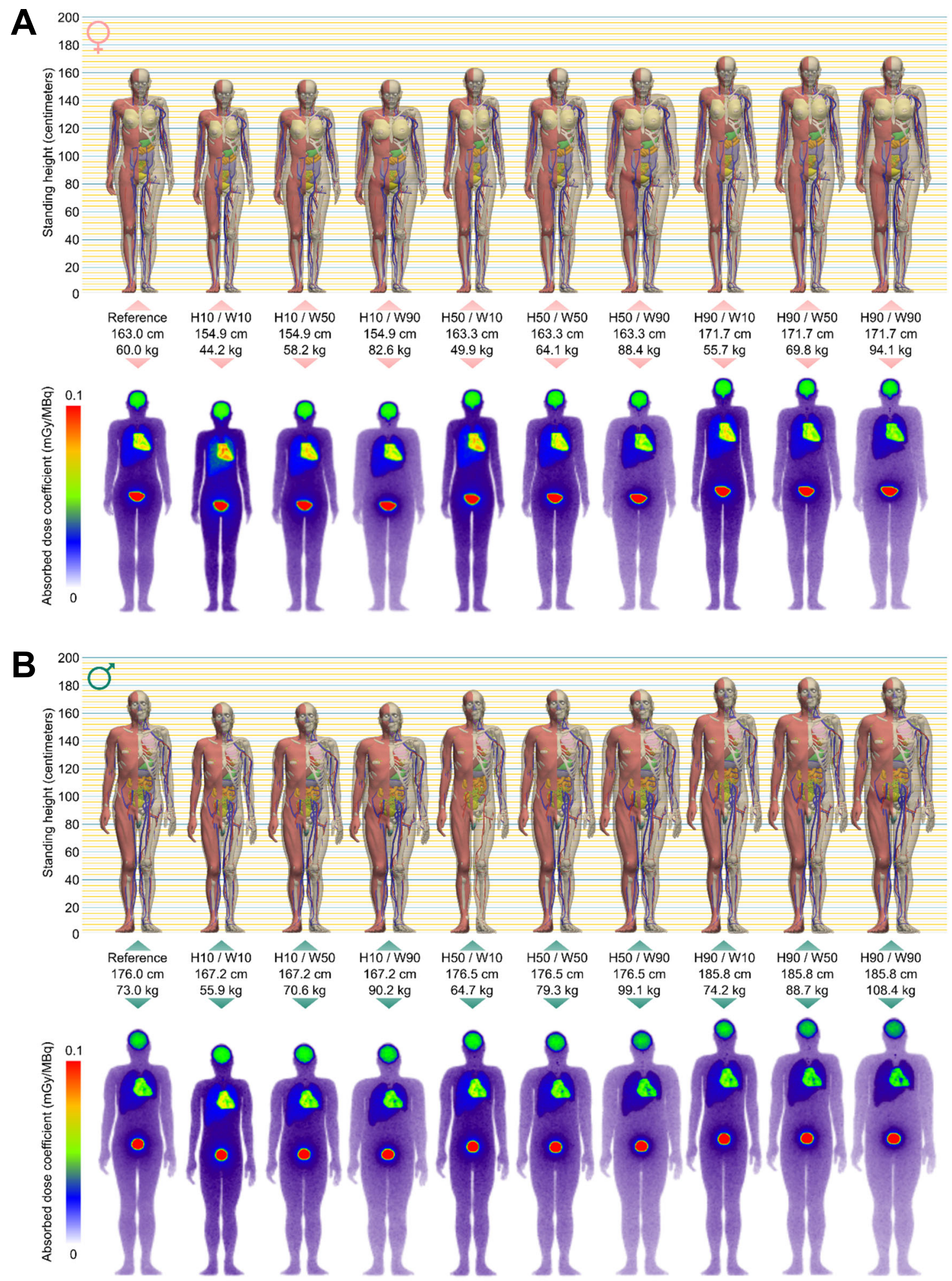

Figure 2: Voxel-level absorbed dose coefficients for 18F-FDG. A) The adult female reference and percentilespecific phantom series juxtaposed with maximum intensity projections of their corresponding $18 \mathrm{~F}-\mathrm{FDG}$ voxel dose coefficient maps. B) Same as (A) but for the adult male. $\mathrm{Hx}=x^{\text {th }}$ percentile standing height; Wy $=y^{\text {th }}$ weight percentile within preceding standing height percentile. 


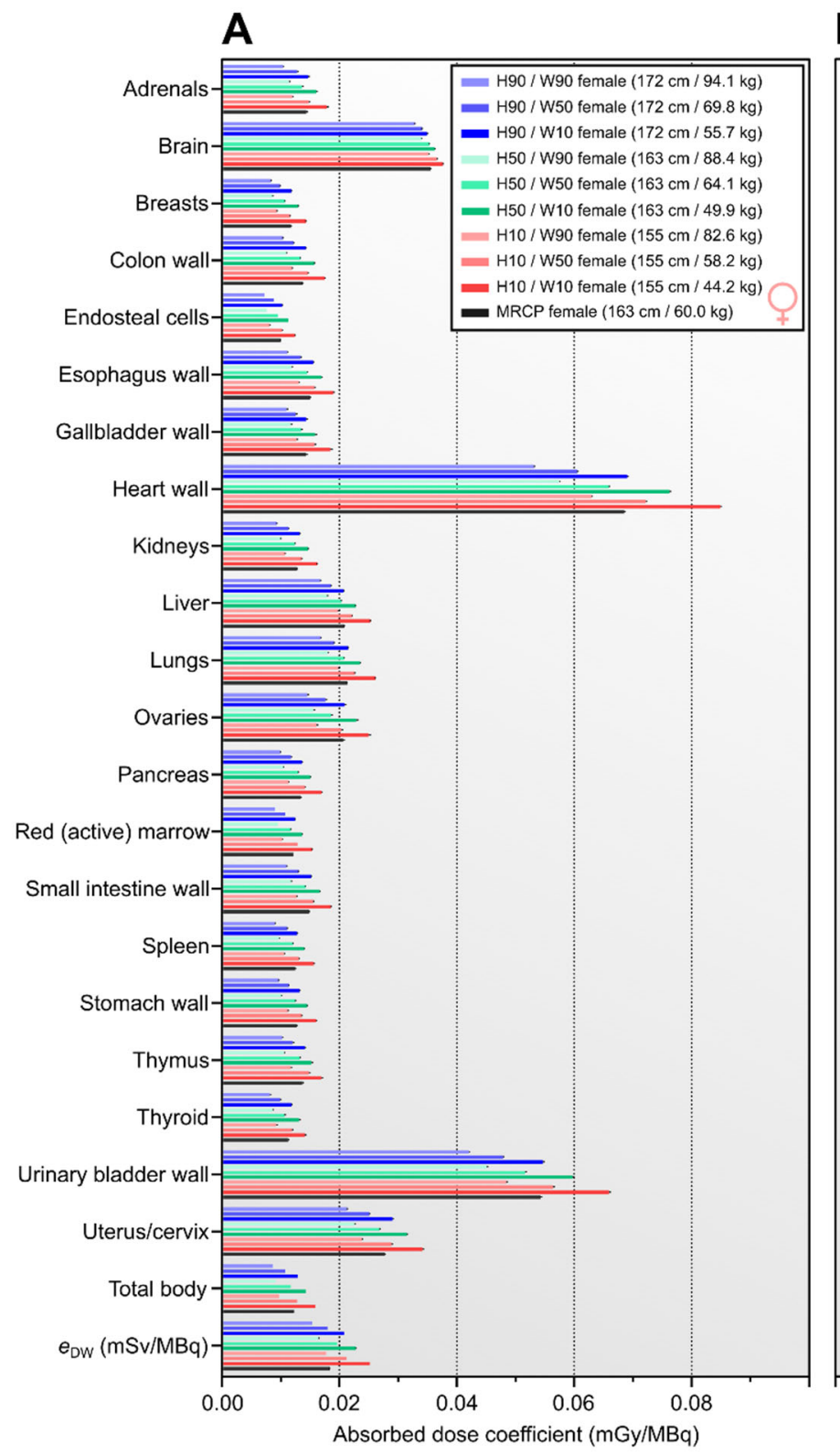

B

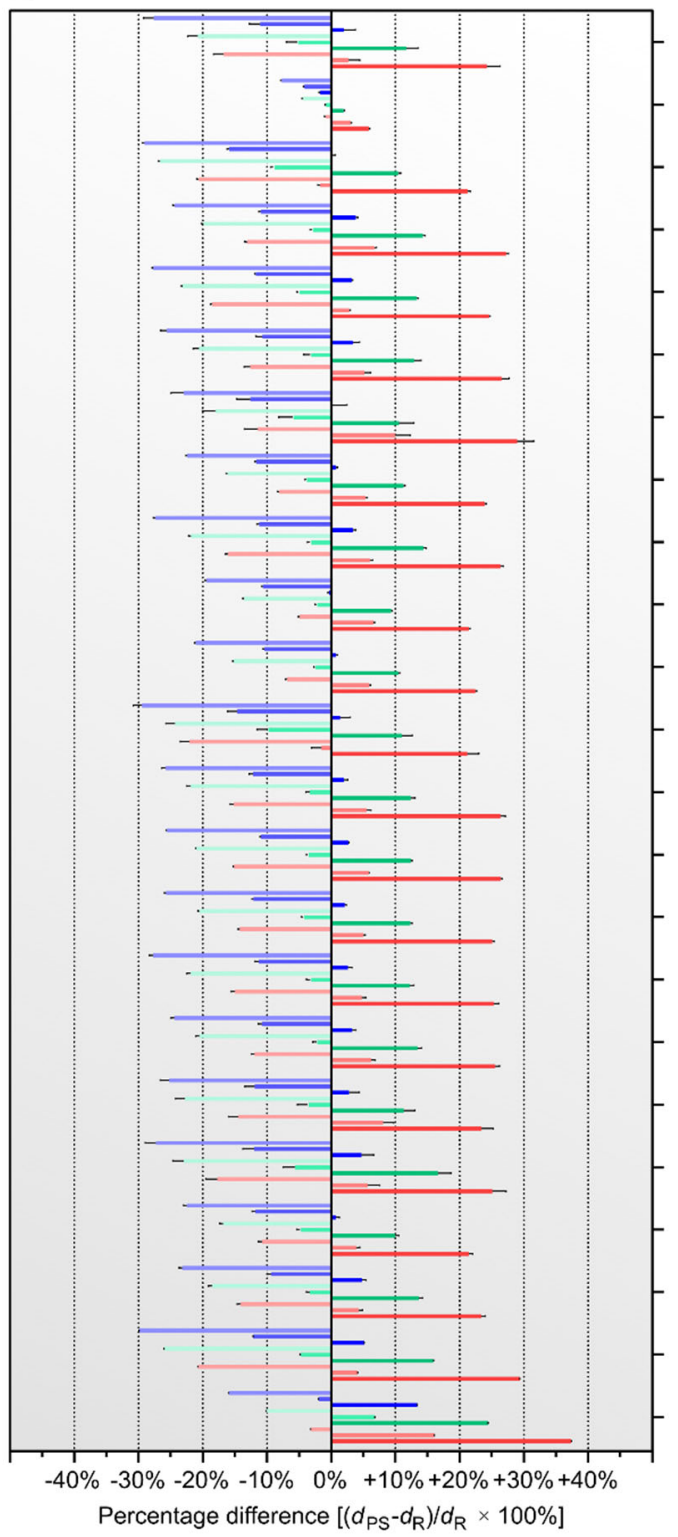

Figure 3: A) Organ-level absorbed dose coefficients for ${ }^{18 F-F D G ~ f o r ~ t h e ~ f e m a l e ~ m e s h ~ r e f e r e n c e ~}$ computational phantom (MRCP) and comparison with percentile-specific phantom series. B) Percentile specific dose coefficients presented as fractional differences relative to the reference female. 


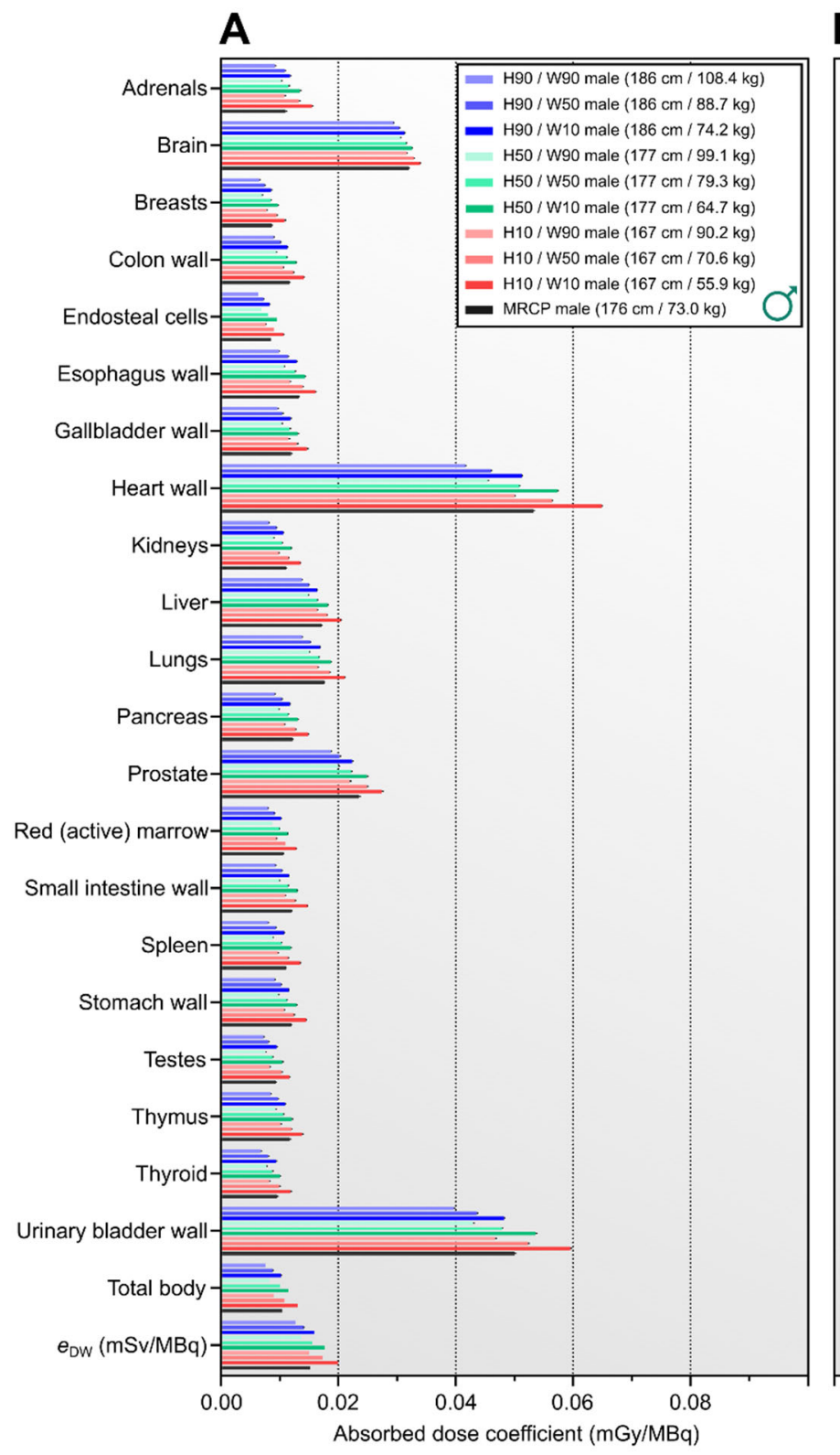

B

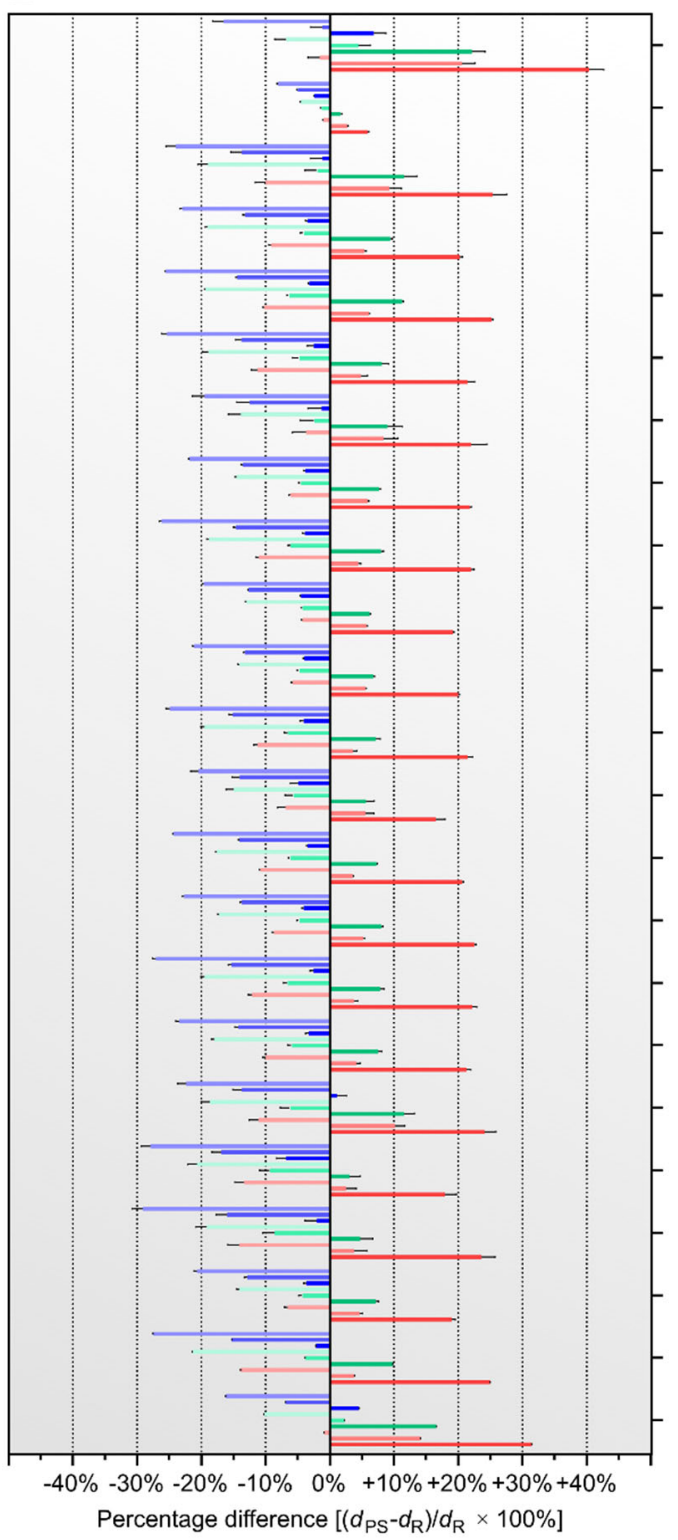

Figure 4: A) Organ-level absorbed dose coefficients for ${ }^{18} \mathrm{~F}-\mathrm{FDG}$ for the male mesh reference computational phantom and comparison with the percentile-specific phantom series. B) Percentile specific dose coefficients presented as fractional differences relative to the reference male. 


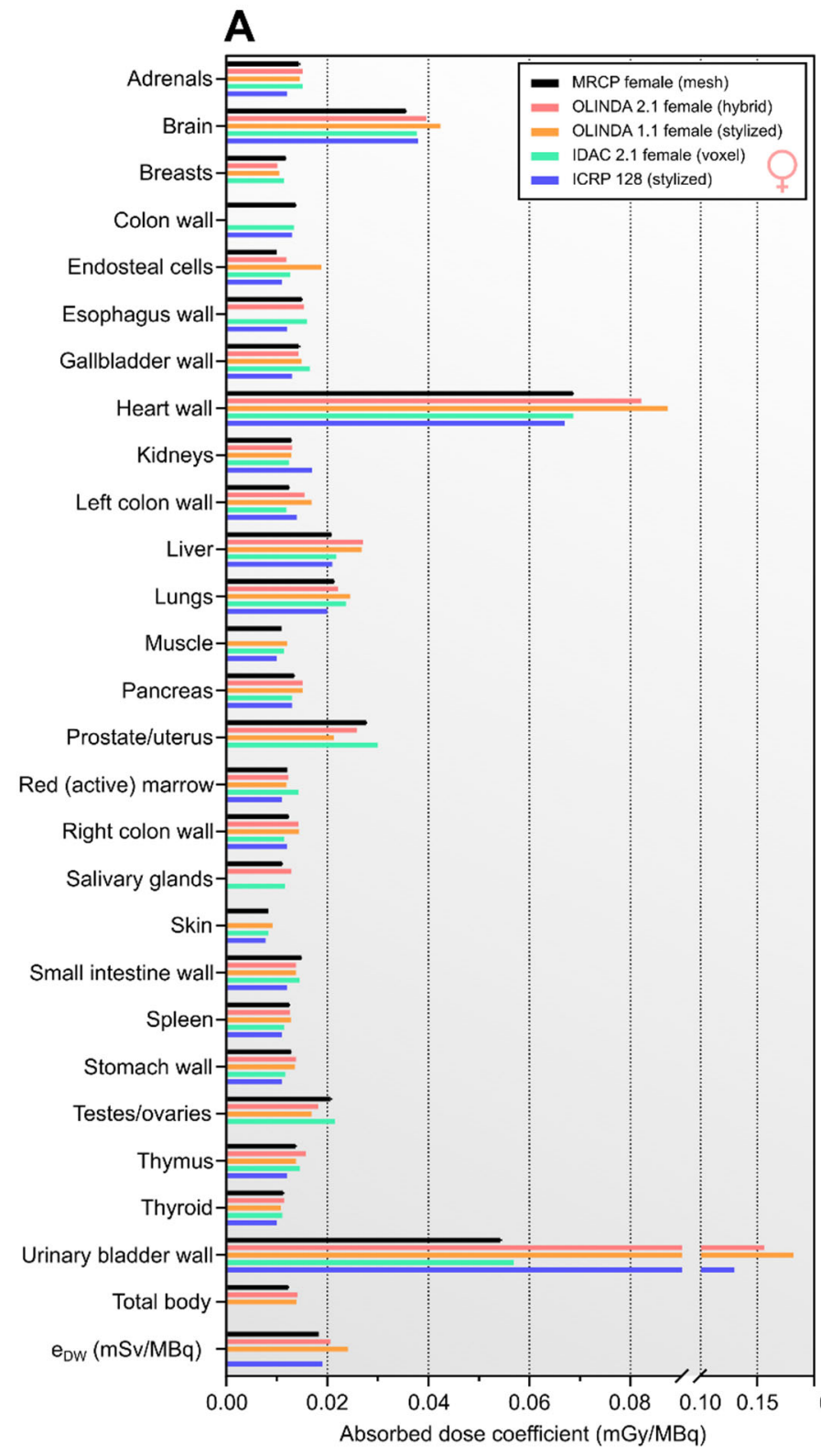

B

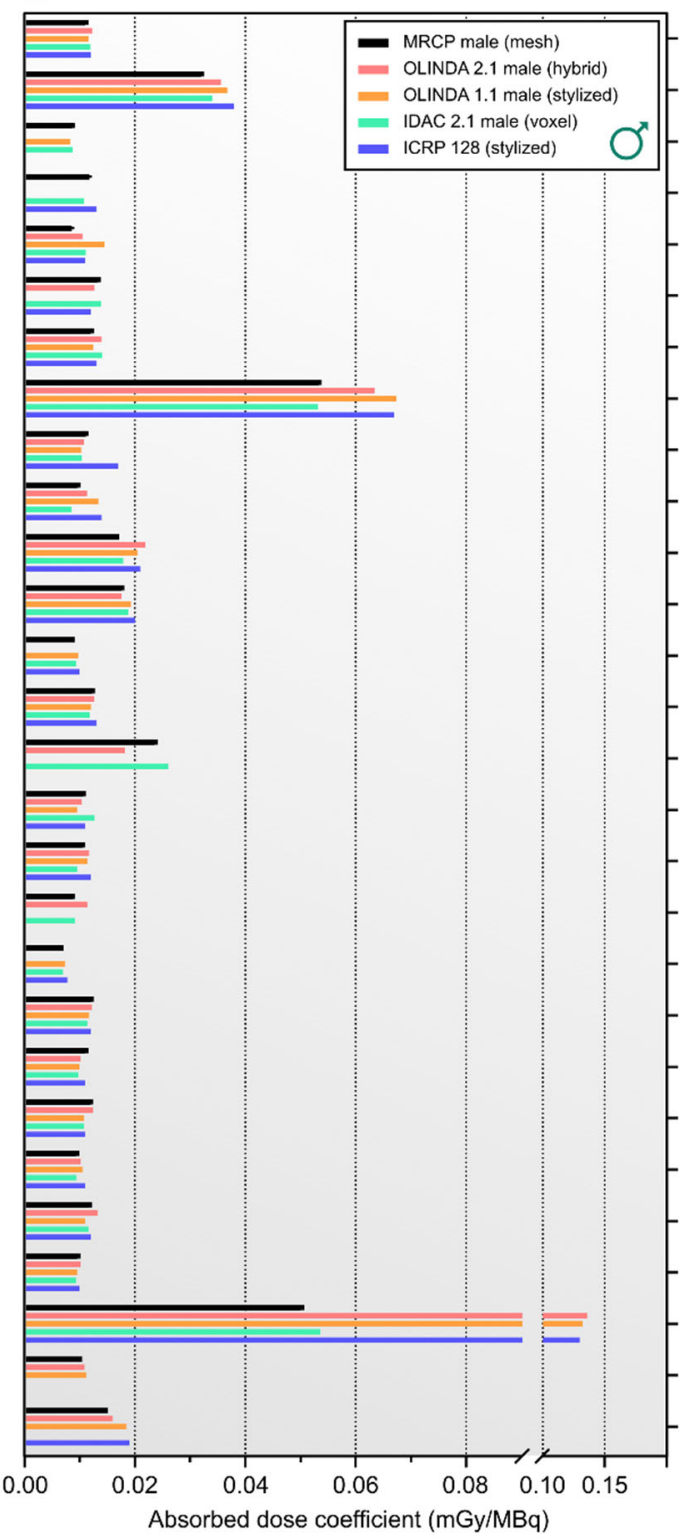

Figure 5: Comparison of organ-level dosimetry computed with reference phantoms in modern and legacy dosimetry software. Note the overall improved agreement between the mesh reference adults and the output of IDAC-dose 2.1, where anatomically equivalent phantoms were represented by different formats (i.e. mesh vs. voxel). 

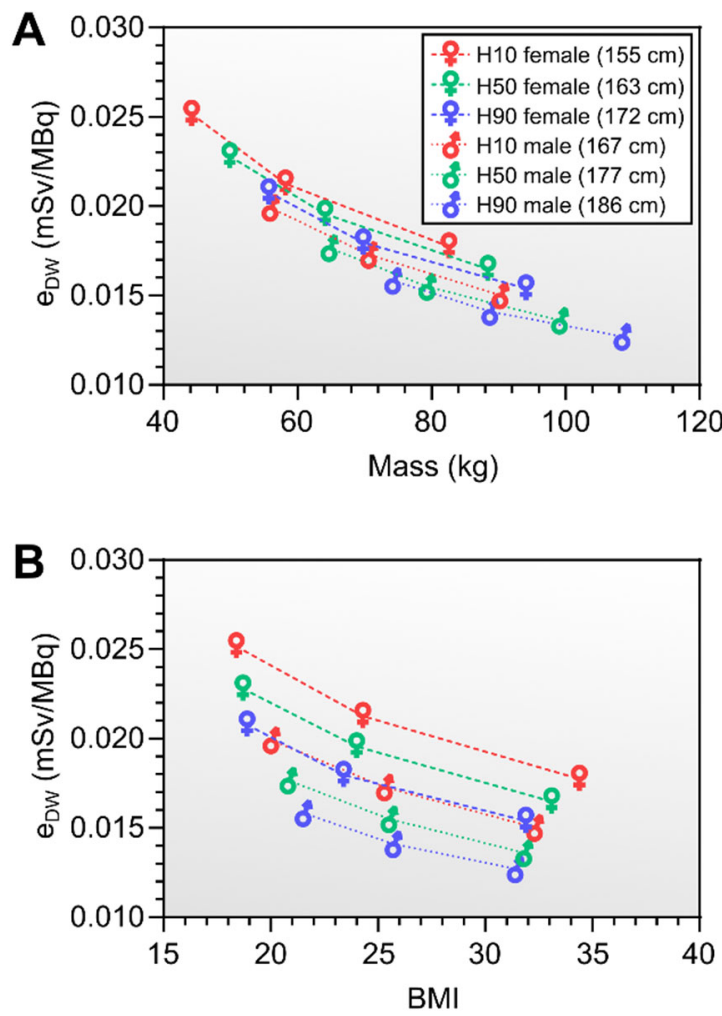

Figure 6: A) Dependence on body mass, and B) dependence on body mass index (BMI), of detrimentweighted dose coefficients for the male and female percentile specific phantom series. 
Table 1: ICRP 128 reference organ time-integrated activity coefficients used in the present study.

\begin{tabular}{lc}
\hline Source organ/tissue & TIAC (h) \\
\hline Brain & 0.21 \\
Heart wall & 0.11 \\
Lungs (alveolar interstitium) & 0.079 \\
Liver & 0.13 \\
Urinary bladder contents & 0.26 \\
Rest of body* & 1.7 \\
\hline *Represents all other tissues - except for mineral bone, teeth, air within the \\
body, and contents of the gastrointestinal tract - to which the associated TIAC is \\
apportioned based on mass.
\end{tabular}


Table 2: Characteristics of phantoms as-implemented in software used in the present study.

\begin{tabular}{|c|c|c|c|c|c|}
\hline $\begin{array}{l}\text { Phantom name } \\
\text { (software } \\
\text { implementation) }\end{array}$ & $\begin{array}{c}\text { Morphometric } \\
\text { category }\end{array}$ & Format & $\begin{array}{c}\text { Source/target } \\
\text { regions }\end{array}$ & $\begin{array}{c}\text { Tissue } \\
\text { weighting } \\
\text { factors } \div\end{array}$ & Reference \\
\hline $\begin{array}{l}\text { Mesh reference } \\
\text { (PARaDIM) }\end{array}$ & Reference & $\begin{array}{l}\text { Tetrahedral } \\
\text { mesh }\end{array}$ & 190 & ICRP 103 & $(20)$ \\
\hline $\begin{array}{l}\text { Percentile-specific } \\
\text { (PARaDIM) }\end{array}$ & Patient-dependent & $\begin{array}{l}\text { Tetrahedral } \\
\text { mesh }\end{array}$ & 190 & ICRP 103 & $(22)$ \\
\hline $\begin{array}{l}\text { ICRP } 89 \text { adult } \\
\text { (OLINDA } 2.1)\end{array}$ & Reference & Hybrid* & $\begin{array}{l}27 / 25(\mathrm{M}) \\
28 / 26(\mathrm{~F})\end{array}$ & ICRP 103 & $(19,39)$ \\
\hline $\begin{array}{l}\text { Cristy-Eckerman adult } \\
\text { (OLINDA 1.1) }\end{array}$ & Reference & Stylized & $\begin{array}{c}26 / 25 * *(\mathrm{M}) \\
25 / 24(\mathrm{~F})\end{array}$ & ICRP 60 & $(8,33)$ \\
\hline $\begin{array}{l}\text { Cristy-Eckerman adult } \\
\text { (ICRP 128) }\end{array}$ & Reference & Stylized & $28 \dagger$ & ICRP 60 & $(8,11)$ \\
\hline $\begin{array}{l}\text { ICRP } 110 \text { adult } \\
\text { (IDAC-dose } 2.1 \text { ) }\end{array}$ & Reference & Voxel & $79 / 47$ & ICRP 103 & $(40,41)$ \\
\hline
\end{tabular}




\section{Graphical Abstract:}

\section{Reference dosimetry $>>$ Personalization > > Patient-dependent dosimetry}

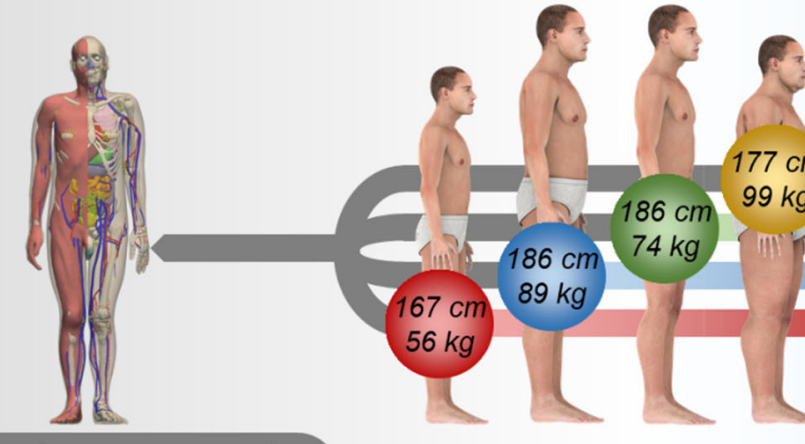

Reference phantom representing single 'average patient'

Key finding: Patient anatomic variability

Reference dose coefficients impacts ${ }^{18} F-F D G$ dosimetry $\pm 40 \%$
Patient-dependent dose coefficients 
Supplementary Table S1: ${ }^{18} \mathrm{~F}-\mathrm{FDG}$ organ-level absorbed dose coefficients ( $\mathrm{mGy} / \mathrm{MBq}$ ) for adult female reference phantoms.

\begin{tabular}{|c|c|c|c|c|}
\hline \multirow[b]{2}{*}{ Organ/tissue } & \multicolumn{4}{|c|}{ Absorbed dose coefficient (mGy/MBq) } \\
\hline & $\begin{array}{l}\text { MRCP adult female } \\
\quad \text { (PARaDIM) }\end{array}$ & $\begin{array}{l}\text { Adult female } \\
\text { (IDAC-dose 2.1) }\end{array}$ & $\begin{array}{l}\text { Adult female } \\
\text { (OLINDA 1.1) }\end{array}$ & $\begin{array}{l}\text { ICRP } 89 \text { adult female } \\
\text { (OLINDA 2.1) }\end{array}$ \\
\hline Red (active) marrow & $0.01213 \pm 0.000014$ & 0.0143 & 0.0119 & 0.0123 \\
\hline Colon wall & $0.013737 \pm 0.000033$ & 0.0134 & -- & -- \\
\hline Stem cells of colon & $0.01302 \pm 0.00023$ & -- & -- & -- \\
\hline Right lung + left lung & $0.021312 \pm 0.000032$ & 0.0237 & 0.0245 & 0.0221 \\
\hline Stomach wall & $0.012764 \pm 0.000052$ & 0.0117 & 0.0136 & 0.0138 \\
\hline Stem cells of stomach & $0.01183 \pm 0.00031$ & -- & -- & -- \\
\hline Breast adipose + breast glandular & $0.011768 \pm 0.000031$ & 0.0114 & 0.0105 & 0.0101 \\
\hline Right ovary + left ovary & $0.02062 \pm 0.00023$ & 0.0215 & 0.0169 & 0.0182 \\
\hline Testes & -- & -- & -- & -- \\
\hline Urinary bladder wall & $0.05426 \pm 0.0002$ & 0.0569 & 0.182 & 0.156 \\
\hline Urinary bladder basal cells & $0.09012 \pm 0.00088$ & -- & -- & -- \\
\hline Esophagus wall & $0.01497 \pm 0.00011$ & 0.016 & -- & 0.0154 \\
\hline Esophagus basal cells & $0.01281 \pm 0.00065$ & -- & -- & -- \\
\hline Liver & $0.020802 \pm 0.000027$ & 0.0218 & 0.0268 & 0.0271 \\
\hline Thyroid & $0.01126 \pm 0.00015$ & 0.0111 & 0.0108 & 0.0115 \\
\hline $\begin{array}{l}\text { 50um endosteal region (endosteal } \\
\text { cells) }\end{array}$ & $0.009982 \pm 0.000012$ & 0.0127 & 0.0189 & 0.0119 \\
\hline Brain & $0.035548 \pm 0.000043$ & 0.0377 & 0.0424 & 0.0396 \\
\hline Salivary glands & $0.011032 \pm 0.000078$ & 0.0116 & -- & 0.0129 \\
\hline Skin & $0.008345 \pm 0.000011$ & 0.00834 & 0.00911 & -- \\
\hline Basal cells of skin & $0.006693 \pm 0.000027$ & -- & -- & -- \\
\hline Right adrenal + left adrenal & $0.01437 \pm 0.00018$ & 0.0151 & 0.0146 & 0.0151 \\
\hline ET region & $0.01163 \pm 0.00014$ & 0.00993 & -- & -- \\
\hline Gallbladder wall & $0.01432 \pm 0.00022$ & 0.0165 & 0.0149 & 0.0143 \\
\hline Heart wall & $0.06853 \pm 0.00011$ & 0.0687 & 0.0874 & 0.0821 \\
\hline Right kidney + left kidney & $0.012808 \pm 0.000038$ & 0.0124 & 0.0129 & 0.013 \\
\hline Systemic lymph nodes & $0.014099 \pm 0.00006$ & 0.0146 & -- & -- \\
\hline
\end{tabular}




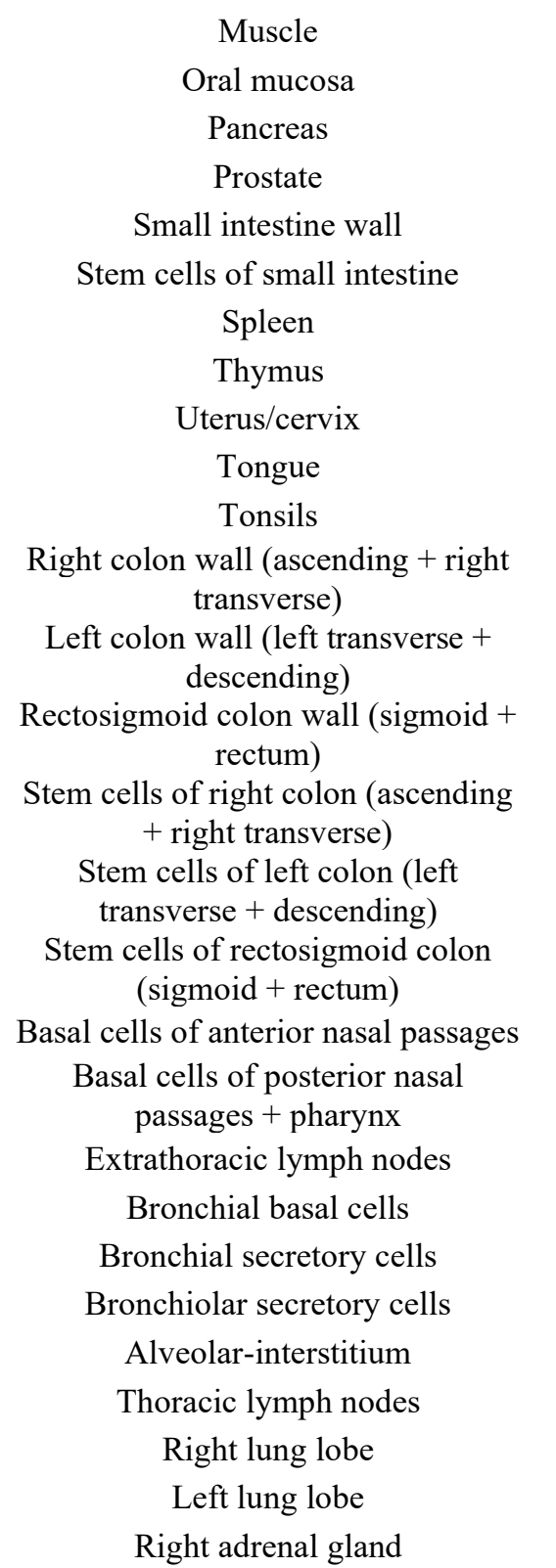

$0.010937 \pm 0.0000057$

$0.01019 \pm 0.00059$

0.0114

0.0112

$0.013396 \pm 0.000062$

0.013

--

$0.014844 \pm 0.000028$

$--$

0.0151

0.0151

0.0145

$--$

$-$

$0.01358 \pm 0.0002$

0.0138

0.0138

$0.012479 \pm 0.000054$

0.0115

0.0128

$-$

$0.0137 \pm 0.00016$

0.0138

0.0126

$0.02771 \pm 0.00011$

0.0146

0.0158

$0.011183 \pm 0.000086$

0.0213

0.0259

0.00823

$0.01218 \pm 0.00037$

0.0122

$0.012307 \pm 0.00005$

0.0115

$--$

$--$

$0.012376 \pm 0.00005$

0.0119

0.0144

0.0143

$0.019514 \pm 0.000085$

0.0169

0.0155

$0.01104 \pm 0.00032$

$0.01157 \pm 0.00041$

$0.01861 \pm 0.00057$

$$
0.01 \pm 0.0019
$$

$0.01303 \pm 0.00088$

$0.01264 \pm 0.00018$

$0.0214 \pm 0.0015$

$0.0213 \pm 0.0015$

$$
\text { -- }
$$

$0.021312 \pm 0.000032$

$0.01375 \pm 0.00019$

$0.021223 \pm 0.000042$

$0.02142 \pm 0.000047$

$0.01433 \pm 0.00024$

0.0202

$--$

$--$

0.0256

0.00727

0.00993

0.00766

0.0206

0.0206

0.0252

0.0252

0.0127

--

$-$

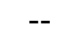

$-$

$-$ 
Left adrenal gland

Right breast adipose

Right breast glandular

Left breast adipose

Left breast glandular

Right breast (adipose + glandular)

Left breast (adipose + glandular)

Breast (adipose)

Breast (glandular)

Entire lenses of eye

Sensitive lenses of eye

Right kidney cortex

Right kidney medulla

Right kidney pelvis

Right kidney (cortex + medulla + pelvis)

Left kidney cortex

Left kidney medulla

Left kidney pelvis

Left kidney (cortex + medulla + pelvis)

Right ovary

Left ovary

Pituitary gland

Spinal cord

Ureters

Adipose/residual tissue

Total body

$e_{\mathrm{DW}}$ or $e(\mathrm{mSv} / \mathrm{MBq})$
$0.01441 \pm 0.00027$

$0.010936 \pm 0.000054$

$0.011192 \pm 0.000069$

$0.011576 \pm 0.000056$

$0.012056 \pm 0.000071$

$0.011039 \pm 0.000042$

$0.011768 \pm 0.000044$

$0.011576 \pm 0.000039$

$0.012056 \pm 0.00005$

$0.01094 \pm 0.00088$

$0.0131 \pm 0.0021$

$0.013276 \pm 0.000065$

$0.01315 \pm 0.00012$

$0.01371 \pm 0.00027$

$0.013268 \pm 0.000056$

$0.01241 \pm 0.000058$

$0.01248 \pm 0.00011$

$0.01235 \pm 0.00024$

$0.012421 \pm 0.000051$

$0.02006 \pm 0.00032$

$0.02062 \pm 0.00033$

$0.0215 \pm 0.0011$

$0.01271 \pm 0.00015$

$0.0153 \pm 0.00018$

$0.0104791 \pm 0.0000047$

$0.0122857 \pm 0.0000033$

$0.0183177 \pm 0.0000033$

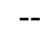

0.00926

--

$-$

$--$

$--$

$--$

$-$

$--$

--

0.0217

--

0.0166

0.0107

--

0.0161
0.0129

0.0141

0.0206 
Supplementary Table S2: ${ }^{18} \mathrm{~F}-\mathrm{FDG}$ organ-level absorbed dose coefficients (mGy/MBq) for adult male reference phantoms.

\begin{tabular}{|c|c|c|c|c|}
\hline \multirow[b]{2}{*}{ Organ/tissue } & \multicolumn{4}{|c|}{ Absorbed dose coefficient (mGy/MBq) } \\
\hline & $\begin{array}{l}\text { MRCP adult male } \\
\text { (PARaDIM) }\end{array}$ & $\begin{array}{c}\text { Adult male } \\
\text { (IDAC-dose 2.1) }\end{array}$ & $\begin{array}{l}\text { Adult male } \\
\text { (OLINDA 1.1) }\end{array}$ & $\begin{array}{l}\text { ICRP } 89 \text { adult male } \\
\text { (OLINDA 2.1) }\end{array}$ \\
\hline Red (active) marrow & $0.010647 \pm 0.000012$ & 0.0127 & 0.00959 & 0.0104 \\
\hline Colon wall & $0.01174 \pm 0.000029$ & 0.0107 & -- & -- \\
\hline Stem cells of colon & $0.01085 \pm 0.00021$ & -- & -- & -- \\
\hline Right lung + left lung & $0.01759 \pm 0.000026$ & 0.0188 & 0.0193 & 0.0176 \\
\hline Stomach wall & $0.011973 \pm 0.000046$ & 0.0107 & 0.0107 & 0.0124 \\
\hline Stem cells of stomach & $0.01016 \pm 0.00026$ & -- & -- & -- \\
\hline Breast adipose + breast glandular & $0.00865 \pm 0.00011$ & 0.00874 & 0.00827 & -- \\
\hline Right ovary + left ovary & -- & -- & 0.0135 & -- \\
\hline Testes & $0.009375 \pm 0.000098$ & 0.00943 & 0.0105 & 0.0102 \\
\hline Urinary bladder wall & $0.05002 \pm 0.00017$ & 0.0536 & 0.132 & 0.136 \\
\hline Urinary bladder basal cells & $0.08941 \pm 0.00091$ & -- & -- & -- \\
\hline Esophagus wall & $0.013262 \pm 0.000092$ & 0.0138 & -- & 0.0127 \\
\hline Esophagus basal cells & $0.01274 \pm 0.00063$ & -- & -- & -- \\
\hline Liver & $0.017163 \pm 0.000021$ & 0.0179 & 0.0205 & 0.0219 \\
\hline Thyroid & $0.00958 \pm 0.00013$ & 0.00935 & 0.0096 & 0.0101 \\
\hline $\begin{array}{l}\text { 50um endosteal region (endosteal } \\
\text { cells) }\end{array}$ & $0.0085496 \pm 0.0000095$ & 0.0111 & 0.0145 & 0.0105 \\
\hline Brain & $0.032021 \pm 0.000038$ & 0.034 & 0.0368 & 0.0356 \\
\hline Salivary glands & $0.00868 \pm 0.000063$ & 0.00916 & -- & 0.0114 \\
\hline Skin & $0.0070636 \pm 0.0000083$ & 0.007 & 0.00736 & -- \\
\hline Basal cells of skin & $0.005614 \pm 0.000023$ & -- & -- & -- \\
\hline Right adrenal + left adrenal & $0.01102 \pm 0.00015$ & 0.0119 & 0.0116 & 0.0123 \\
\hline ET region & $0.009422 \pm 0.00009$ & 0.00858 & -- & -- \\
\hline Gallbladder wall & $0.01196 \pm 0.00018$ & 0.0141 & 0.0125 & 0.014 \\
\hline Heart wall & $0.053279 \pm 0.000085$ & 0.0532 & 0.0674 & 0.0634 \\
\hline Right kidney + left kidney & $0.011098 \pm 0.000032$ & 0.0104 & 0.0103 & 0.0107 \\
\hline Systemic lymph nodes & $0.012935 \pm 0.000052$ & 0.0133 & -- & -- \\
\hline
\end{tabular}




Muscle
Oral mucosa
Pancreas
Prostate
Small intestine wall
Stem cells of small intestine
Spleen
Thymus
Uterus/cervix
Tongue
Tonsils
transverse)
descending)
Right colon wall (asending + right
Left colon wall (left transverse +
Rectosigmoid colon wall (sigmoid +
rectum)
Stem cells of right colon (ascending
+ right transverse)
Stem cells of left colon (left
transverse + descending)
Stem cells of rectosigmoid colon
(sigmoid + rectum)
Basal cells of anterior nasal passages
Basal cells of posterior nasal
passages + pharynx
Extrathoracic lymph nodes
Bronchial basal cells
Bronchial secretory cells
Bronchiolar secretory cells
Alveolar-interstitium
Thoracic lymph nodes
Right lung lobe
Left lung lobe
Right adrenal gland

$0.0090788 \pm 0.0000037$

$0.00888 \pm 0.00047$

0.00973

$0.012247 \pm 0.000054$

0.0118

$0.02352 \pm 0.00021$

0.0261

$0.012067 \pm 0.000022$

0.0114

$0.01109 \pm 0.00016$

$--$

$0.011052 \pm 0.000045$

0.00979

$0.01171 \pm 0.00013$

0.0116

$0.00931 \pm 0.00007$

0.00751

$0.01217 \pm 0.00037$

0.0127

$0.010522 \pm 0.000043$

0.00955

0.00854

0.00974

$--$

0.0121

0.0126

0.0182

0.0122

$-$

$--$

0.01

0.011

0.0101

0.0179

0.0133

$0.009657 \pm 0.000042$

0.0175

$0.00988 \pm 0.00032$

$0.00911 \pm 0.00034$

$0.01457 \pm 0.00048$

$0.0087 \pm 0.0011$

0.0114

0.0117

0.0134

0.0113

$0.01061 \pm 0.00065$

$0.01058 \pm 0.00015$

$0.01575 \pm 0.00084$

$0.01569 \pm 0.00084$

$0.01759 \pm 0.000026$

$0.01222 \pm 0.00016$

$0.017566 \pm 0.000035$

$0.017619 \pm 0.000039$

$0.01204 \pm 0.00022$

--
--
--
0.00524
0.00858
0.00585
0.015
0.015
0.0207
0.0206
0.0108
--
--
--

0.0157 


\begin{tabular}{|c|c|c|c|c|}
\hline Left adrenal gland & $0.01102 \pm 0.00021$ & -- & -- & -- \\
\hline Right breast adipose & $0.00909 \pm 0.00021$ & -- & -- & -- \\
\hline Right breast glandular & $0.00788 \pm 0.00023$ & -- & -- & -- \\
\hline Left breast adipose & $0.00903 \pm 0.00021$ & -- & -- & -- \\
\hline Left breast glandular & $0.00808 \pm 0.00024$ & -- & -- & -- \\
\hline Right breast (adipose + glandular) & $0.0086 \pm 0.00016$ & -- & -- & -- \\
\hline Left breast (adipose + glandular) & $0.00865 \pm 0.00016$ & -- & -- & -- \\
\hline Breast (adipose) & $0.00903 \pm 0.00015$ & -- & -- & -- \\
\hline Breast (glandular) & $0.00808 \pm 0.00017$ & -- & -- & -- \\
\hline Entire lenses of eye & $0.00927 \pm 0.00082$ & 0.00811 & -- & 0.0103 \\
\hline Sensitive lenses of eye & $0.0064 \pm 0.0015$ & -- & -- & -- \\
\hline Right kidney cortex & $0.011438 \pm 0.000053$ & -- & -- & -- \\
\hline Right kidney medulla & $0.01168 \pm 0.0001$ & -- & -- & -- \\
\hline Right kidney pelvis & $0.01224 \pm 0.00023$ & -- & -- & -- \\
\hline $\begin{array}{l}\text { Right kidney (cortex }+ \text { medulla }+ \\
\text { pelvis) }\end{array}$ & $0.011512 \pm 0.000046$ & -- & -- & -- \\
\hline Left kidney cortex & $0.010648 \pm 0.000051$ & -- & -- & -- \\
\hline Left kidney medulla & $0.01073 \pm 0.0001$ & -- & -- & -- \\
\hline Left kidney pelvis & $0.01088 \pm 0.00022$ & -- & -- & -- \\
\hline $\begin{array}{c}\text { Left kidney (cortex }+ \text { medulla }+ \\
\text { pelvis) }\end{array}$ & $0.010672 \pm 0.000045$ & -- & -- & -- \\
\hline Right ovary & -- & -- & -- & -- \\
\hline Left ovary & -- & -- & -- & -- \\
\hline Pituitary gland & $0.01833 \pm 0.00098$ & 0.0197 & -- & -- \\
\hline Spinal cord & $0.010817 \pm 0.0001$ & -- & -- & -- \\
\hline Ureters & $0.01463 \pm 0.00017$ & 0.0146 & -- & -- \\
\hline Adipose/residual tissue & $0.0093647 \pm 0.0000047$ & 0.0096 & -- & -- \\
\hline Total body & $0.0104552 \pm 0.0000027$ & -- & 0.0112 & 0.0109 \\
\hline$e_{\mathrm{DW}}$ or $e(\mathrm{mSv} / \mathrm{MBq})$ & $0.0151539 \pm 0.0000033$ & 0.0161 & 0.0185 & 0.016 \\
\hline
\end{tabular}


Supplementary Table S3: ${ }^{18} \mathrm{~F}-\mathrm{FDG}$ organ-level absorbed dose coefficients (mGy/MBq) for the $10^{\text {th }}$ percentile standing height adult female PSPs.

\begin{tabular}{|c|c|c|c|}
\hline \multirow[b]{2}{*}{ Organ/tissue } & \multicolumn{3}{|c|}{ Absorbed dose coefficient (mGy/MBq) } \\
\hline & $\begin{array}{l}\text { H10 / W10 female } \\
(155 \mathrm{~cm} / 44.2 \mathrm{~kg})\end{array}$ & $\begin{array}{l}\text { H10 / W50 female } \\
(155 \mathrm{~cm} / 58.2 \mathrm{~kg})\end{array}$ & $\begin{array}{l}\text { H10 / W90 female } \\
(155 \mathrm{~cm} / 82.6 \mathrm{~kg})\end{array}$ \\
\hline Red (active) marrow & $0.015334 \pm 0.000018$ & $0.012833 \pm 0.000015$ & $0.010297 \pm 0.000012$ \\
\hline Colon wall & $0.017473 \pm 0.000042$ & $0.014658 \pm 0.000035$ & $0.011937 \pm 0.000028$ \\
\hline Stem cells of colon & $0.01653 \pm 0.00029$ & $0.01435 \pm 0.00025$ & $0.01167 \pm 0.00022$ \\
\hline Right lung + left lung & $0.026091 \pm 0.00004$ & $0.022572 \pm 0.000033$ & $0.019841 \pm 0.000029$ \\
\hline Stomach wall & $0.016024 \pm 0.000065$ & $0.013563 \pm 0.000055$ & $0.011242 \pm 0.000045$ \\
\hline Stem cells of stomach & $0.01398 \pm 0.00037$ & $0.0119 \pm 0.00031$ & $0.01012 \pm 0.00026$ \\
\hline Breast adipose + breast glandular & $0.014271 \pm 0.000041$ & $0.011565 \pm 0.000031$ & $0.009342 \pm 0.000022$ \\
\hline Right ovary + left ovary & $0.02499 \pm 0.00029$ & $0.02031 \pm 0.00024$ & $0.01608 \pm 0.00019$ \\
\hline Testes & -- & -- & -- \\
\hline Urinary bladder wall & $0.06589 \pm 0.00024$ & $0.05637 \pm 0.0002$ & $0.04839 \pm 0.00018$ \\
\hline Urinary bladder basal cells & $0.11854 \pm 0.001$ & $0.10008 \pm 0.00085$ & $0.08589 \pm 0.00074$ \\
\hline Esophagus wall & $0.01894 \pm 0.00014$ & $0.01574 \pm 0.00011$ & $0.013079 \pm 0.000094$ \\
\hline Esophagus basal cells & $0.01782 \pm 0.00086$ & $0.0154 \pm 0.00075$ & $0.01266 \pm 0.00064$ \\
\hline Liver & $0.025256 \pm 0.000033$ & $0.022164 \pm 0.000029$ & $0.019771 \pm 0.000024$ \\
\hline Thyroid & $0.01408 \pm 0.00019$ & $0.01189 \pm 0.00016$ & $0.00926 \pm 0.00013$ \\
\hline $\begin{array}{l}\text { 50um endosteal region (endosteal } \\
\text { cells) }\end{array}$ & $0.012432 \pm 0.000015$ & $0.010259 \pm 0.000013$ & $0.008124 \pm 0.00001$ \\
\hline Brain & $0.037615 \pm 0.000045$ & $0.036608 \pm 0.000044$ & $0.035228 \pm 0.000042$ \\
\hline Salivary glands & $0.013904 \pm 0.000096$ & $0.011245 \pm 0.00008$ & $0.008813 \pm 0.000067$ \\
\hline Skin & $0.011073 \pm 0.000014$ & $0.008728 \pm 0.000011$ & $0.006281 \pm 0.0000084$ \\
\hline Basal cells of skin & $0.008799 \pm 0.000034$ & $0.006952 \pm 0.000029$ & $0.005219 \pm 0.000022$ \\
\hline Right adrenal + left adrenal & $0.01784 \pm 0.00023$ & $0.01475 \pm 0.00019$ & $0.01197 \pm 0.00015$ \\
\hline ET region & $0.01445 \pm 0.00017$ & $0.01181 \pm 0.00015$ & $0.00927 \pm 0.00012$ \\
\hline Gallbladder wall & $0.01846 \pm 0.00029$ & $0.01575 \pm 0.00024$ & $0.01268 \pm 0.0002$ \\
\hline Heart wall & $0.0849 \pm 0.00014$ & $0.07222 \pm 0.00012$ & $0.06295 \pm 0.0001$ \\
\hline Right kidney + left kidney & $0.016184 \pm 0.000047$ & $0.013585 \pm 0.000039$ & $0.010749 \pm 0.000031$ \\
\hline Systemic lymph nodes & $0.01784 \pm 0.000074$ & $0.014961 \pm 0.000061$ & $0.012048 \pm 0.000049$ \\
\hline
\end{tabular}


Muscle

Oral mucosa

Pancreas

Prostate

Small intestine wall

Stem cells of small intestine

Spleen

Thymus

Uterus/cervix

Tongue

Tonsils

Right colon wall (ascending + right transverse)

Left colon wall (left transverse + descending)

Rectosigmoid colon wall (sigmoid + rectum)

Stem cells of right colon (ascending + right transverse)

Stem cells of left colon (left transverse + descending)

Stem cells of rectosigmoid colon (sigmoid + rectum)

Basal cells of anterior nasal passages

Basal cells of posterior nasal passages + pharynx

Extrathoracic lymph nodes

Bronchial basal cells

Bronchial secretory cells

Bronchiolar secretory cells

Alveolar-interstitium

Thoracic lymph nodes

Right lung lobe

Left lung lobe

Right adrenal gland
$0.013979 \pm 0.0000056$

$0.01264 \pm 0.0007$

$0.016924 \pm 0.000078$

$0.018565 \pm 0.000035$

$0.01702 \pm 0.00024$

$0.015641 \pm 0.000069$

$0.01691 \pm 0.0002$

$0.03418 \pm 0.00014$

$0.01415 \pm 0.00011$

$0.01554 \pm 0.00046$

$0.015622 \pm 0.000063$

$0.015855 \pm 0.000065$

$0.02449 \pm 0.00013$

$0.01434 \pm 0.0004$

$0.01458 \pm 0.0005$

$0.02316 \pm 0.0007$

$0.0131 \pm 0.0028$

$0.025 \pm 0.0026$

$0.01589 \pm 0.00022$

$0.0247 \pm 0.0017$

$0.024 \pm 0.0018$

$-$

$0.026091 \pm 0.00004$

$0.01722 \pm 0.00024$

$0.025962 \pm 0.000055$

$0.026249 \pm 0.000058$

$0.01785 \pm 0.00031$
$0.011284 \pm 0.0000056$

$0.00997 \pm 0.00058$

$0.014136 \pm 0.000065$

$-$

$0.015591 \pm 0.000029$

$0.01417 \pm 0.00021$

$0.013071 \pm 0.000056$

$0.01481 \pm 0.00017$

$0.0289 \pm 0.00012$

$0.011383 \pm 0.000089$

$0.01158 \pm 0.00037$

$0.013245 \pm 0.000052$

$0.013315 \pm 0.000054$

$0.02018 \pm 0.00011$

$0.01237 \pm 0.00034$

$0.0124 \pm 0.00042$

$0.0206 \pm 0.00064$

$0.0112 \pm 0.002$

$0.0187 \pm 0.0021$

$0.01344 \pm 0.00019$

$0.0187 \pm 0.0014$

$0.0202 \pm 0.0015$

$--$

$0.022572 \pm 0.000033$

$0.01488 \pm 0.0002$

$0.022524 \pm 0.000045$

$0.022631 \pm 0.00005$

$0.01482 \pm 0.00025$
$0.0086685 \pm 0.0000043$

$0.00769 \pm 0.00051$

$0.011366 \pm 0.000051$

$$
-
$$

$0.012732 \pm 0.000024$

$0.01193 \pm 0.00018$

$0.010608 \pm 0.000046$

$0.01172 \pm 0.00013$

$0.023798 \pm 0.000095$

$0.008811 \pm 0.000072$

$0.00973 \pm 0.00032$

$0.010818 \pm 0.000043$

$0.010855 \pm 0.000043$

$0.016496 \pm 0.000089$

$0.00984 \pm 0.00029$

$0.01078 \pm 0.00037$

$0.0163 \pm 0.00053$

$0.0066 \pm 0.0016$

$0.0152 \pm 0.0017$

$0.01058 \pm 0.00016$

$0.0166 \pm 0.0013$

$0.0166 \pm 0.0014$

$$
--
$$

$0.019841 \pm 0.000029$

$0.01148 \pm 0.00016$

$0.019797 \pm 0.00004$

$0.019895 \pm 0.000044$

$0.01192 \pm 0.0002$ 
Left adrenal gland

Right breast adipose

Right breast glandular

Left breast adipose

Left breast glandular

Right breast (adipose + glandular)

Left breast (adipose + glandular)

Breast (adipose)

Breast (glandular)

Entire lenses of eye

Sensitive lenses of eye

Right kidney cortex

Right kidney medulla

Right kidney pelvis

Right kidney (cortex + medulla + pelvis)

Left kidney cortex

Left kidney medulla

Left kidney pelvis

Left kidney (cortex + medulla + pelvis)

Right ovary

Left ovary

Pituitary gland

Spinal cord

Ureters

Adipose/residual tissue

Total body

$e_{\mathrm{DW}}$ or $e(\mathrm{mSv} / \mathrm{MBq})$
$0.01783 \pm 0.00034$

$0.014238 \pm 0.000077$

$0.014311 \pm 0.000087$

$0.014691 \pm 0.000078$

$0.015602 \pm 0.00009$

$0.014271 \pm 0.000058$

$0.015107 \pm 0.000059$

$0.014238 \pm 0.000054$

$0.014311 \pm 0.000062$

$0.0127 \pm 0.001$

$0.0101 \pm 0.002$

$0.016678 \pm 0.000082$

$0.01676 \pm 0.00016$

$0.0168 \pm 0.00035$

$0.016698 \pm 0.000071$

$0.015602 \pm 0.000073$

$0.01551 \pm 0.00014$

$0.01623 \pm 0.00031$

$0.015608 \pm 0.000064$

$0.02499 \pm 0.00041$

$0.0255 \pm 0.00041$

$0.0228 \pm 0.0012$

$0.01572 \pm 0.00019$

$0.01981 \pm 0.00023$

$0.013802 \pm 0.0000055$

$0.0158901 \pm 0.0000039$

$0.0251598 \pm 0.0000049$
$0.01465 \pm 0.00028$

$0.011474 \pm 0.000055$

$0.011711 \pm 0.000073$

$0.011993 \pm 0.000056$

$0.01262 \pm 0.000074$

$0.011565 \pm 0.000044$

$0.012233 \pm 0.000045$

$0.011474 \pm 0.000039$

$0.011711 \pm 0.000051$

$0.0121 \pm 0.001$

$0.0113 \pm 0.002$

$0.013987 \pm 0.000069$

$0.01413 \pm 0.00013$

$0.0142 \pm 0.00028$

$0.014022 \pm 0.000059$

$0.013165 \pm 0.000062$

$0.01296 \pm 0.00012$

$0.01289 \pm 0.00025$

$0.013114 \pm 0.000053$

$0.02031 \pm 0.00033$

$0.02167 \pm 0.00034$

$0.0225 \pm 0.0011$

$0.01299 \pm 0.00016$

$0.01624 \pm 0.00018$

$0.010997 \pm 0.0000044$

$0.0127871 \pm 0.0000033$

$0.0212562 \pm 0.0000035$
$0.01203 \pm 0.00023$

$0.009286 \pm 0.000036$

$0.009482 \pm 0.000058$

$0.009793 \pm 0.000037$

$0.010257 \pm 0.000061$

$0.009342 \pm 0.000031$

$0.009925 \pm 0.000032$

$0.009286 \pm 0.000026$

$0.009482 \pm 0.000041$

$0.00635 \pm 0.00064$

$0.0072 \pm 0.0015$

$0.011172 \pm 0.000055$

$0.01126 \pm 0.00011$

$0.01125 \pm 0.00023$

$0.011192 \pm 0.000048$

$0.010312 \pm 0.000049$

$0.010182 \pm 0.000092$

$0.01029 \pm 0.0002$

$0.010286 \pm 0.000043$

$0.01608 \pm 0.00027$

$0.01676 \pm 0.00027$

$0.01731 \pm 0.00089$

$0.01042 \pm 0.00013$

$0.01304 \pm 0.00015$

$0.0083336 \pm 0.0000025$

$0.0097375 \pm 0.0000022$

$0.0177345 \pm 0.0000026$ 
Supplementary Table S4: ${ }^{18} \mathrm{~F}-\mathrm{FDG}$ organ-level absorbed dose coefficients (mGy/MBq) for the $50^{\text {th }}$ percentile standing height adult female PSPs.

\begin{tabular}{|c|c|c|c|}
\hline \multirow[b]{2}{*}{ Organ/tissue } & \multicolumn{3}{|c|}{ Absorbed dose coefficient (mGy/MBq) } \\
\hline & $\begin{array}{l}\text { H50 / W10 female } \\
(163 \mathrm{~cm} / 49.9 \mathrm{~kg})\end{array}$ & $\begin{array}{l}\text { H50 / W50 female } \\
(163 \mathrm{~cm} / 64.1 \mathrm{~kg})\end{array}$ & $\begin{array}{l}\text { H50 / W90 female } \\
(163 \mathrm{~cm} / 88.4 \mathrm{~kg})\end{array}$ \\
\hline Red (active) marrow & $0.013634 \pm 0.000016$ & $0.011682 \pm 0.000014$ & $0.009585 \pm 0.000011$ \\
\hline Colon wall & $0.015696 \pm 0.000038$ & $0.013327 \pm 0.000032$ & $0.011004 \pm 0.000026$ \\
\hline Stem cells of colon & $0.0147 \pm 0.00026$ & $0.01309 \pm 0.00024$ & $0.01083 \pm 0.0002$ \\
\hline Right lung + left lung & $0.023533 \pm 0.000036$ & $0.020768 \pm 0.000031$ & $0.018083 \pm 0.000027$ \\
\hline Stomach wall & $0.014479 \pm 0.000059$ & $0.012473 \pm 0.000049$ & $0.010142 \pm 0.000041$ \\
\hline Stem cells of stomach & $0.0128 \pm 0.00034$ & $0.01154 \pm 0.0003$ & $0.00932 \pm 0.00025$ \\
\hline Breast adipose + breast glandular & $0.012993 \pm 0.000037$ & $0.010703 \pm 0.000028$ & $0.008636 \pm 0.000021$ \\
\hline Right ovary + left ovary & $0.02287 \pm 0.00026$ & $0.01856 \pm 0.00021$ & $0.01561 \pm 0.00018$ \\
\hline Testes & -- & -- & -- \\
\hline Urinary bladder wall & $0.05968 \pm 0.00022$ & $0.05163 \pm 0.00019$ & $0.04511 \pm 0.00016$ \\
\hline Urinary bladder basal cells & $0.10669 \pm 0.00091$ & $0.09122 \pm 0.00078$ & $0.07834 \pm 0.00067$ \\
\hline Esophagus wall & $0.0169 \pm 0.00012$ & $0.01448 \pm 0.0001$ & $0.011888 \pm 0.000085$ \\
\hline Esophagus basal cells & $0.01591 \pm 0.00077$ & $0.01396 \pm 0.0007$ & $0.01156 \pm 0.0006$ \\
\hline Liver & $0.022741 \pm 0.00003$ & $0.020317 \pm 0.000024$ & $0.017978 \pm 0.000022$ \\
\hline Thyroid & $0.01313 \pm 0.00017$ & $0.01062 \pm 0.00014$ & $0.00867 \pm 0.00012$ \\
\hline $\begin{array}{l}\text { 50um endosteal region (endosteal } \\
\text { cells) }\end{array}$ & $0.011315 \pm 0.000014$ & $0.009466 \pm 0.000012$ & $0.0076684 \pm 0.0000097$ \\
\hline Brain & $0.036225 \pm 0.000043$ & $0.035266 \pm 0.000042$ & $0.033984 \pm 0.000041$ \\
\hline Salivary glands & $0.012855 \pm 0.000089$ & $0.010565 \pm 0.000076$ & $0.00835 \pm 0.000063$ \\
\hline Skin & $0.009779 \pm 0.000012$ & $0.0079561 \pm 0.0000099$ & $0.0058909 \pm 0.0000079$ \\
\hline Basal cells of skin & $0.007869 \pm 0.000031$ & $0.006379 \pm 0.000026$ & $0.00489 \pm 0.000021$ \\
\hline Right adrenal + left adrenal & $0.01604 \pm 0.0002$ & $0.01361 \pm 0.00017$ & $0.01138 \pm 0.00014$ \\
\hline ET region & $0.01306 \pm 0.00016$ & $0.01098 \pm 0.00014$ & $0.00881 \pm 0.00012$ \\
\hline Gallbladder wall & $0.01583 \pm 0.00025$ & $0.01346 \pm 0.00021$ & $0.01173 \pm 0.00018$ \\
\hline Heart wall & $0.07625 \pm 0.00012$ & $0.06587 \pm 0.00011$ & $0.05745 \pm 0.000092$ \\
\hline Right kidney + left kidney & $0.014645 \pm 0.000043$ & $0.012384 \pm 0.000035$ & $0.010012 \pm 0.000029$ \\
\hline Systemic lymph nodes & $0.016022 \pm 0.000066$ & $0.013618 \pm 0.000055$ & $0.011164 \pm 0.000045$ \\
\hline
\end{tabular}


Muscle

Oral mucosa

Pancreas

Prostate

Small intestine wall

Stem cells of small intestine

Spleen

Thymus

Uterus/cervix

Tongue

Tonsils

Right colon wall (ascending + right transverse)

Left colon wall (left transverse + descending)

Rectosigmoid colon wall (sigmoid + rectum)

Stem cells of right colon (ascending + right transverse)

Stem cells of left colon (left transverse + descending)

Stem cells of rectosigmoid colon (sigmoid + rectum)

Basal cells of anterior nasal passages

Basal cells of posterior nasal passages + pharynx

Extrathoracic lymph nodes

Bronchial basal cells

Bronchial secretory cells

Bronchiolar secretory cells

Alveolar-interstitium

Thoracic lymph nodes

Right lung lobe

Left lung lobe

Right adrenal gland
$0.012582 \pm 0.000005$

$0.01257 \pm 0.00071$

$0.015052 \pm 0.000069$

$0.01667 \pm 0.000031$

$0.01571 \pm 0.00022$

$0.014005 \pm 0.00006$

$0.01524 \pm 0.00018$

$0.03147 \pm 0.00012$

$0.012787 \pm 0.000097$

$0.01354 \pm 0.00041$

$0.013923 \pm 0.000056$

$0.014236 \pm 0.000058$

$0.02215 \pm 0.00012$

$0.01273 \pm 0.00036$

$0.0125 \pm 0.00043$

$0.02119 \pm 0.00064$

$0.0149 \pm 0.0023$

$0.0244 \pm 0.0025$

$0.01432 \pm 0.0002$

$0.0227 \pm 0.0016$

$0.0242 \pm 0.0017$

$-$

$0.023533 \pm 0.000036$

$0.01539 \pm 0.00021$

$0.023444 \pm 0.000049$

$0.023641 \pm 0.000052$

$0.01601 \pm 0.00027$
$0.010326 \pm 0.0000052$

$0.01084 \pm 0.0006$

$0.01295 \pm 0.000058$

$0.014188 \pm 0.000026$

$0.01322 \pm 0.00019$

$0.012071 \pm 0.000051$

$0.01319 \pm 0.00015$

$0.02679 \pm 0.0001$

$0.010506 \pm 0.000083$

$0.01092 \pm 0.00035$

$0.011985 \pm 0.000047$

$0.012005 \pm 0.000049$

$0.0187 \pm 0.000099$

$0.01109 \pm 0.00031$

$0.01185 \pm 0.00041$

$0.01847 \pm 0.00059$

$0.0076 \pm 0.0014$

$0.0173 \pm 0.002$

$0.01198 \pm 0.00018$

$0.0182 \pm 0.0014$

$0.017 \pm 0.0013$

$-$

$0.020768 \pm 0.00003$

$0.01346 \pm 0.00018$

$0.020682 \pm 0.000041$

$0.020872 \pm 0.000046$

$0.01358 \pm 0.00023$
$0.0081449 \pm 0.0000041$

$0.00784 \pm 0.0005$

$0.010458 \pm 0.000048$

$0.011796 \pm 0.000022$ $0.01096 \pm 0.00016$

$0.009742 \pm 0.000042$

$0.01058 \pm 0.00012$

$0.022556 \pm 0.000088$

$0.008342 \pm 0.000069$

$0.00932 \pm 0.00031$

$0.010004 \pm 0.000039$

$0.009857 \pm 0.00004$

$0.015476 \pm 0.000082$

$0.00925 \pm 0.00027$

$0.00962 \pm 0.00035$

$0.01538 \pm 0.00048$

$0.0067 \pm 0.0013$

$0.0145 \pm 0.0015$

$0.00997 \pm 0.00015$

$0.0151 \pm 0.0011$

$0.0158 \pm 0.0012$$$
-
$$

$0.018083 \pm 0.000027$

$0.01061 \pm 0.00015$

$0.01803 \pm 0.000036$

$0.018147 \pm 0.00004$

$0.01158 \pm 0.00019$ 
Left adrenal gland

Right breast adipose

Right breast glandular

Left breast adipose

Left breast glandular

Right breast (adipose + glandular)

Left breast (adipose + glandular)

Breast (adipose)

Breast (glandular)

Entire lenses of eye

Sensitive lenses of eye

Right kidney cortex

Right kidney medulla

Right kidney pelvis

Right kidney (cortex + medulla + pelvis)

Left kidney cortex

Left kidney medulla

Left kidney pelvis

Left kidney (cortex + medulla + pelvis)

Right ovary

Left ovary

Pituitary gland

Spinal cord

Ureters

Adipose/residual tissue

Total body

$e_{\mathrm{DW}}$ or $e(\mathrm{mSv} / \mathrm{MBq})$
$0.01608 \pm 0.00031$

$0.012862 \pm 0.000068$

$0.013153 \pm 0.000079$

$0.013579 \pm 0.000071$

$0.014177 \pm 0.000081$

$0.012993 \pm 0.000052$

$0.013847 \pm 0.000053$

$0.012862 \pm 0.000048$

$0.013153 \pm 0.000056$

$0.01242 \pm 0.00099$

$0.0116 \pm 0.0019$

$0.015006 \pm 0.000075$

$0.01485 \pm 0.00014$

$0.01523 \pm 0.0003$

$0.014985 \pm 0.000065$

$0.014221 \pm 0.000067$

$0.01431 \pm 0.00013$

$0.01484 \pm 0.00028$

$0.014262 \pm 0.000058$

$0.02287 \pm 0.00037$

$0.02401 \pm 0.00038$

$0.0206 \pm 0.0011$

$0.01433 \pm 0.00017$

$0.01715 \pm 0.0002$

$0.012349 \pm 0.0000049$

$0.0142377 \pm 0.0000035$

$0.0227877 \pm 0.000004$
$0.01365 \pm 0.00026$

$0.010552 \pm 0.00005$

$0.010946 \pm 0.000067$

$0.011169 \pm 0.000051$

$0.011682 \pm 0.000068$

$0.010703 \pm 0.00004$

$0.011366 \pm 0.000041$

$0.010552 \pm 0.000035$

$0.010946 \pm 0.000047$

$0.01038 \pm 0.00089$

$0.0111 \pm 0.0021$

$0.012723 \pm 0.000062$

$0.01255 \pm 0.00012$

$0.0134 \pm 0.00026$

$0.012716 \pm 0.000054$

$0.011996 \pm 0.000055$

$0.01205 \pm 0.00011$

$0.01215 \pm 0.00023$

$0.012012 \pm 0.000048$

$0.01856 \pm 0.0003$

$0.01985 \pm 0.00031$

$0.01846 \pm 0.00096$

$0.01215 \pm 0.00014$

$0.01472 \pm 0.00017$

$0.010023 \pm 0.000004$

$0.0116895 \pm 0.000003$

$0.0195576 \pm 0.000003$
$0.01113 \pm 0.00021$

$0.008584 \pm 0.000034$

$0.008761 \pm 0.000054$

$0.008955 \pm 0.000035$

$0.009502 \pm 0.000055$

$0.008636 \pm 0.000029$

$0.009116 \pm 0.00003$

$0.008584 \pm 0.000024$

$0.008761 \pm 0.000038$

$0.00762 \pm 0.00067$

$0.0075 \pm 0.0014$

$0.010385 \pm 0.000051$

$0.010395 \pm 0.000096$

$0.01077 \pm 0.00021$

$0.010402 \pm 0.000044$

$0.00958 \pm 0.000045$

$0.009548 \pm 0.000086$

$0.00964 \pm 0.00019$

$0.009576 \pm 0.000039$

$0.01561 \pm 0.00025$

$0.01611 \pm 0.00025$

$0.01562 \pm 0.00085$

$0.00956 \pm 0.00012$

$0.01276 \pm 0.00014$

$0.0077491 \pm 0.0000023$

$0.0090949 \pm 0.0000021$

$0.0164682 \pm 0.0000022$ 
Supplementary Table S5: ${ }^{18}$ F-FDG organ-level absorbed dose coefficients (mGy/MBq) for the $90^{\text {th }}$ percentile standing height adult female PSPs.

\begin{tabular}{|c|c|c|c|}
\hline \multirow[b]{2}{*}{ Organ/tissue } & \multicolumn{3}{|c|}{ Absorbed dose coefficient (mGy/MBq) } \\
\hline & $\begin{array}{l}\text { H90 / W10 female } \\
(172 \mathrm{~cm} / 55.7 \mathrm{~kg})\end{array}$ & $\begin{array}{l}\text { H90 / W50 female } \\
(172 \mathrm{~cm} / 69.8 \mathrm{~kg})\end{array}$ & $\begin{array}{l}\text { H90 / W90 female } \\
(172 \mathrm{~cm} / 94.1 \mathrm{~kg})\end{array}$ \\
\hline Red (active) marrow & $0.012448 \pm 0.000015$ & $0.010804 \pm 0.000013$ & $0.009027 \pm 0.000011$ \\
\hline Colon wall & $0.014262 \pm 0.000034$ & $0.01223 \pm 0.000029$ & $0.010389 \pm 0.000024$ \\
\hline Stem cells of colon & $0.01414 \pm 0.00025$ & $0.0113 \pm 0.00021$ & $0.0104 \pm 0.00019$ \\
\hline Right lung + left lung & $0.021473 \pm 0.000032$ & $0.019091 \pm 0.000028$ & $0.016812 \pm 0.000025$ \\
\hline Stomach wall & $0.013184 \pm 0.000054$ & $0.011382 \pm 0.000045$ & $0.009647 \pm 0.000038$ \\
\hline Stem cells of stomach & $0.01151 \pm 0.0003$ & $0.01026 \pm 0.00027$ & $0.00833 \pm 0.00022$ \\
\hline Breast adipose + breast glandular & $0.011798 \pm 0.000033$ & $0.009898 \pm 0.000026$ & $0.008348 \pm 0.00002$ \\
\hline Right ovary + left ovary & $0.0209 \pm 0.00023$ & $0.0176 \pm 0.0002$ & $0.01455 \pm 0.00016$ \\
\hline Testes & -- & -- & -- \\
\hline Urinary bladder wall & $0.05467 \pm 0.0002$ & $0.04784 \pm 0.00017$ & $0.04204 \pm 0.00015$ \\
\hline Urinary bladder basal cells & $0.09665 \pm 0.00082$ & $0.08404 \pm 0.00072$ & $0.07277 \pm 0.00063$ \\
\hline Esophagus wall & $0.01547 \pm 0.00011$ & $0.013363 \pm 0.000095$ & $0.011136 \pm 0.000079$ \\
\hline Esophagus basal cells & $0.01319 \pm 0.00064$ & $0.01204 \pm 0.00059$ & $0.01085 \pm 0.00054$ \\
\hline Liver & $0.020727 \pm 0.000027$ & $0.018583 \pm 0.000024$ & $0.016756 \pm 0.00002$ \\
\hline Thyroid & $0.01179 \pm 0.00015$ & $0.00991 \pm 0.00013$ & $0.00819 \pm 0.00011$ \\
\hline $\begin{array}{l}\text { 50um endosteal region (endosteal } \\
\text { cells) }\end{array}$ & $0.010297 \pm 0.000013$ & $0.008808 \pm 0.000011$ & $0.0072138 \pm 0.0000091$ \\
\hline Brain & $0.034933 \pm 0.000042$ & $0.034069 \pm 0.000041$ & $0.032807 \pm 0.000039$ \\
\hline Salivary glands & $0.011605 \pm 0.000082$ & $0.009676 \pm 0.00007$ & $0.007841 \pm 0.00006$ \\
\hline Skin & $0.008833 \pm 0.000011$ & $0.0072457 \pm 0.0000097$ & $0.0055504 \pm 0.0000074$ \\
\hline Basal cells of skin & $0.007097 \pm 0.000028$ & $0.005917 \pm 0.000025$ & $0.00457 \pm 0.00002$ \\
\hline Right adrenal + left adrenal & $0.01465 \pm 0.00018$ & $0.01278 \pm 0.00016$ & $0.0104 \pm 0.00013$ \\
\hline ET region & $0.01197 \pm 0.00015$ & $0.0103 \pm 0.00013$ & $0.00833 \pm 0.00011$ \\
\hline Gallbladder wall & $0.01435 \pm 0.00023$ & $0.01251 \pm 0.00019$ & $0.01103 \pm 0.00017$ \\
\hline Heart wall & $0.06903 \pm 0.00011$ & $0.060533 \pm 0.000097$ & $0.053162 \pm 0.000085$ \\
\hline Right kidney + left kidney & $0.013239 \pm 0.000038$ & $0.011373 \pm 0.000033$ & $0.009306 \pm 0.000027$ \\
\hline Systemic lymph nodes & $0.01462 \pm 0.000059$ & $0.012566 \pm 0.000051$ & $0.010473 \pm 0.000042$ \\
\hline
\end{tabular}


Muscle

Oral mucosa

Pancreas

Prostate

Small intestine wall

Stem cells of small intestine

Spleen

Thymus

Uterus/cervix

Tongue

Tonsils

Right colon wall (ascending + right transverse)

Left colon wall (left transverse + descending)

Rectosigmoid colon wall (sigmoid + rectum)

Stem cells of right colon (ascending + right transverse)

Stem cells of left colon (left transverse + descending)

Stem cells of rectosigmoid colon (sigmoid + rectum)

Basal cells of anterior nasal passages

Basal cells of posterior nasal passages + pharynx

Extrathoracic lymph nodes

Bronchial basal cells

Bronchial secretory cells

Bronchiolar secretory cells

Alveolar-interstitium

Thoracic lymph nodes

Right lung lobe

Left lung lobe

Right adrenal gland
$0.011407 \pm 0.0000046$

$0.01047 \pm 0.0006$

$0.013655 \pm 0.000063$

$0.015152 \pm 0.000028$ $0.0142 \pm 0.0002$

$0.012806 \pm 0.000055$

$0.01408 \pm 0.00016$

$0.02905 \pm 0.00011$

$0.011754 \pm 0.000091$

$0.01209 \pm 0.00038$

$0.012634 \pm 0.000051$

$0.012835 \pm 0.000052$

$0.02044 \pm 0.00011$

$0.01184 \pm 0.00033$

$0.01255 \pm 0.00042$

$0.02056 \pm 0.00063$

$0.0079 \pm 0.0016$

$0.0212 \pm 0.0023$

$0.01292 \pm 0.00019$

$0.0192 \pm 0.0014$

$0.0199 \pm 0.0014$

$-$

$0.021473 \pm 0.000032$

$0.01377 \pm 0.00019$

$0.021398 \pm 0.000043$

$0.021565 \pm 0.000047$

$0.01466 \pm 0.00025$
$0.0095569 \pm 0.0000048$

$0.00935 \pm 0.00055$

$0.011765 \pm 0.000054$

$-$

$0.013047 \pm 0.000024$

$0.01228 \pm 0.00018$

$0.011071 \pm 0.000048$

$0.01207 \pm 0.00014$

$0.025108 \pm 0.000098$

$0.009838 \pm 0.000077$

$0.00999 \pm 0.00032$

$0.010905 \pm 0.000044$

$0.010975 \pm 0.000045$

$0.017508 \pm 0.000091$

$0.00938 \pm 0.00027$

$0.00985 \pm 0.00036$

$0.01682 \pm 0.00052$

$0.0124 \pm 0.0023$

$0.015 \pm 0.0016$

$0.01144 \pm 0.00017$

$0.0146 \pm 0.0011$

$0.0154 \pm 0.0012$

--

$0.019091 \pm 0.000028$

$0.01216 \pm 0.00016$

$0.019002 \pm 0.000038$

$0.0192 \pm 0.000042$

$0.01271 \pm 0.00021$
$0.0076501 \pm 0.0000038$

$0.00741 \pm 0.00045$

$0.009938 \pm 0.000045$

$$
-
$$

$0.011025 \pm 0.000021$ $0.01046 \pm 0.00015$

$0.009014 \pm 0.000039$

$0.01025 \pm 0.00011$

$0.021279 \pm 0.000083$

$0.007934 \pm 0.000065$

$0.00825 \pm 0.00027$

$0.009418 \pm 0.000037$

$0.009278 \pm 0.000037$

$0.014668 \pm 0.000076$

$0.00926 \pm 0.00026$

$0.00906 \pm 0.00032$

$0.01427 \pm 0.00044$

$0.0054 \pm 0.0012$

$0.014 \pm 0.0015$

$0.00921 \pm 0.00014$

$0.01349 \pm 0.00096$

$0.0149 \pm 0.0011$

$-$

$0.016812 \pm 0.000025$

$0.00986 \pm 0.00013$

$0.016799 \pm 0.000034$

$0.016828 \pm 0.000037$

$0.01015 \pm 0.00017$ 
Left adrenal gland

Right breast adipose

Right breast glandular

Left breast adipose

Left breast glandular

Right breast (adipose + glandular)

Left breast (adipose + glandular)

Breast (adipose)

Breast (glandular)

Entire lenses of eye

Sensitive lenses of eye

Right kidney cortex

Right kidney medulla

Right kidney pelvis

Right kidney (cortex + medulla + pelvis)

Left kidney cortex

Left kidney medulla

Left kidney pelvis

Left kidney (cortex + medulla + pelvis)

Right ovary

Left ovary

Pituitary gland

Spinal cord

Ureters

Adipose/residual tissue

Total body

$e_{\mathrm{DW}}$ or $e(\mathrm{mSv} / \mathrm{MBq})$
$0.01463 \pm 0.00027$

$0.01171 \pm 0.000061$

$0.011909 \pm 0.000071$

$0.012213 \pm 0.000062$

$0.012705 \pm 0.000074$

$0.011798 \pm 0.000046$

$0.012431 \pm 0.000048$

$0.01171 \pm 0.000043$

$0.011909 \pm 0.000051$

$0.01234 \pm 0.00095$

$0.01 \pm 0.0018$

$0.013566 \pm 0.000066$

$0.01362 \pm 0.00013$

$0.01353 \pm 0.00027$

$0.013576 \pm 0.000058$

$0.012865 \pm 0.00006$

$0.01276 \pm 0.00011$

$0.01289 \pm 0.00025$

$0.012845 \pm 0.000052$

$0.0209 \pm 0.00033$

$0.02142 \pm 0.00033$

$0.01925 \pm 0.00099$

$0.01275 \pm 0.00015$

$0.01607 \pm 0.00019$

$0.011153 \pm 0.0000045$

$0.0129123 \pm 0.0000031$

$0.0207713 \pm 0.0000033$
$0.01287 \pm 0.00024$

$0.009774 \pm 0.000046$

$0.010096 \pm 0.000061$

$0.010399 \pm 0.000048$

$0.010872 \pm 0.000062$

$0.009898 \pm 0.000037$

$0.010581 \pm 0.000038$

$0.009774 \pm 0.000032$

$0.010096 \pm 0.000043$

$0.00791 \pm 0.0007$

$0.0081 \pm 0.0015$

$0.011589 \pm 0.000057$

$0.01171 \pm 0.00011$

$0.01209 \pm 0.00024$

$0.011631 \pm 0.000049$

$0.011054 \pm 0.000051$

$0.010996 \pm 0.000097$

$0.01107 \pm 0.00021$

$0.011043 \pm 0.000044$

$0.0176 \pm 0.00028$

$0.01868 \pm 0.00029$

$0.01849 \pm 0.00095$

$0.01137 \pm 0.00013$

$0.01424 \pm 0.00016$

$0.0092322 \pm 0.0000037$

$0.0107934 \pm 0.0000028$

$0.0179528 \pm 0.0000025$
$0.0107 \pm 0.0002$

$0.008345 \pm 0.000033$

$0.008354 \pm 0.00005$

$0.008519 \pm 0.000033$

$0.008971 \pm 0.000052$

$0.008348 \pm 0.000028$

$0.008657 \pm 0.000028$

$0.008345 \pm 0.000024$

$0.008354 \pm 0.000035$

$0.00532 \pm 0.00055$

$0.0046 \pm 0.0013$

$0.009633 \pm 0.000047$

$0.009849 \pm 0.000091$

$0.00977 \pm 0.00019$

$0.00968 \pm 0.000041$

$0.008871 \pm 0.000042$

$0.00898 \pm 0.00008$

$0.00897 \pm 0.00017$

$0.008896 \pm 0.000036$

$0.01455 \pm 0.00023$

$0.01542 \pm 0.00024$

$0.01614 \pm 0.00083$

$0.00891 \pm 0.00011$

$0.01173 \pm 0.00013$

$0.007372 \pm 0.0000022$

$0.0086145 \pm 0.000002$

$0.0153921 \pm 0.0000019$ 
Supplementary Table S6: ${ }^{18} \mathrm{~F}-\mathrm{FDG}$ organ-level absorbed dose coefficients ( $\mathrm{mGy} / \mathrm{MBq}$ ) for the $10^{\text {th }}$ percentile standing height adult male PSPs.

\begin{tabular}{|c|c|c|c|}
\hline \multirow[b]{2}{*}{ Organ/tissue } & \multicolumn{3}{|c|}{ Absorbed dose coefficient (mGy/MBq) } \\
\hline & $\begin{array}{l}\mathrm{H} 10 / \mathrm{W} 10 \text { male } \\
(167 \mathrm{~cm} / 55.9 \mathrm{~kg})\end{array}$ & $\begin{array}{l}\mathrm{H} 10 \text { / W50 male } \\
(167 \mathrm{~cm} / 70.6 \mathrm{~kg})\end{array}$ & $\begin{array}{l}\text { H10 / W90 male } \\
(167 \mathrm{~cm} / 90.2 \mathrm{~kg})\end{array}$ \\
\hline Red (active) marrow & $0.012844 \pm 0.000015$ & $0.011025 \pm 0.000013$ & $0.009494 \pm 0.000011$ \\
\hline Colon wall & $0.014117 \pm 0.000036$ & $0.012369 \pm 0.000031$ & $0.010661 \pm 0.000026$ \\
\hline Stem cells of colon & $0.01322 \pm 0.00027$ & $0.01158 \pm 0.00023$ & $0.00984 \pm 0.0002$ \\
\hline Right lung + left lung & $0.021109 \pm 0.000031$ & $0.018558 \pm 0.000027$ & $0.016574 \pm 0.000025$ \\
\hline Stomach wall & $0.014527 \pm 0.000058$ & $0.012472 \pm 0.000048$ & $0.010783 \pm 0.000042$ \\
\hline Stem cells of stomach & $0.01258 \pm 0.00032$ & $0.01079 \pm 0.00028$ & $0.0093 \pm 0.00024$ \\
\hline Breast adipose + breast glandular & $0.01084 \pm 0.00015$ & $0.00946 \pm 0.00012$ & $0.007787 \pm 0.000086$ \\
\hline Right ovary + left ovary & -- & -- & -- \\
\hline Testes & $0.01164 \pm 0.00012$ & $0.01033 \pm 0.00011$ & $0.008331 \pm 0.000089$ \\
\hline Urinary bladder wall & $0.05952 \pm 0.00021$ & $0.05232 \pm 0.00018$ & $0.04675 \pm 0.00016$ \\
\hline Urinary bladder basal cells & $0.1155 \pm 0.001$ & $0.10054 \pm 0.00089$ & $0.08814 \pm 0.00079$ \\
\hline Esophagus wall & $0.0161 \pm 0.00011$ & $0.013909 \pm 0.000098$ & $0.011764 \pm 0.000082$ \\
\hline Esophagus basal cells & $0.01451 \pm 0.00073$ & $0.01101 \pm 0.0006$ & $0.01188 \pm 0.00062$ \\
\hline Liver & $0.020451 \pm 0.000025$ & $0.018144 \pm 0.000022$ & $0.01643 \pm 0.00002$ \\
\hline Thyroid & $0.01184 \pm 0.00016$ & $0.00994 \pm 0.00013$ & $0.00822 \pm 0.00011$ \\
\hline $\begin{array}{l}\text { 50um endosteal region (endosteal } \\
\text { cells) }\end{array}$ & $0.010705 \pm 0.000012$ & $0.0090691 \pm 0.0000099$ & $0.0076746 \pm 0.0000085$ \\
\hline Brain & $0.03391 \pm 0.000041$ & $0.032878 \pm 0.000039$ & $0.031709 \pm 0.000038$ \\
\hline Salivary glands & $0.011101 \pm 0.000077$ & $0.009283 \pm 0.000066$ & $0.007567 \pm 0.000056$ \\
\hline Skin & $0.008959 \pm 0.00001$ & $0.0072862 \pm 0.0000084$ & $0.0058335 \pm 0.0000073$ \\
\hline Basal cells of skin & $0.007113 \pm 0.000028$ & $0.005811 \pm 0.000024$ & $0.004771 \pm 0.000021$ \\
\hline Right adrenal + left adrenal & $0.01547 \pm 0.00019$ & $0.01329 \pm 0.00016$ & $0.01084 \pm 0.00014$ \\
\hline ET region & $0.01156 \pm 0.00011$ & $0.00974 \pm 0.000093$ & $0.00819 \pm 0.000081$ \\
\hline Gallbladder wall & $0.01459 \pm 0.00022$ & $0.01295 \pm 0.00019$ & $0.01151 \pm 0.00017$ \\
\hline Heart wall & $0.06487 \pm 0.0001$ & $0.0564 \pm 0.00009$ & $0.05 \pm 0.00008$ \\
\hline Right kidney + left kidney & $0.013542 \pm 0.000039$ & $0.011587 \pm 0.000033$ & $0.00987 \pm 0.000028$ \\
\hline Systemic lymph nodes & $0.015907 \pm 0.000061$ & $0.013696 \pm 0.000052$ & $0.011844 \pm 0.000044$ \\
\hline
\end{tabular}


Muscle

Oral mucosa

Pancreas

Prostate

Small intestine wall

Stem cells of small intestine

Spleen

Thymus

Uterus/cervix

Tongue

Tonsils

Right colon wall (ascending + right transverse)

Left colon wall (left transverse + descending)

Rectosigmoid colon wall (sigmoid + rectum)

Stem cells of right colon (ascending + right transverse)

Stem cells of left colon (left transverse + descending)

Stem cells of rectosigmoid colon (sigmoid + rectum)

Basal cells of anterior nasal passages

Basal cells of posterior nasal passages + pharynx

Extrathoracic lymph nodes

Bronchial basal cells

Bronchial secretory cells

Bronchiolar secretory cells

Alveolar-interstitium

Thoracic lymph nodes

Right lung lobe

Left lung lobe

Right adrenal gland
$0.011284 \pm 0.0000045$

$0.01094 \pm 0.00059$

$0.014879 \pm 0.000067$

$0.0274 \pm 0.00025$

$0.014777 \pm 0.000029$

$0.01356 \pm 0.0002$

$0.013507 \pm 0.000057$

$0.01381 \pm 0.00016$

$0.011388 \pm 0.000085$

$0.01369 \pm 0.00042$

$0.012808 \pm 0.000054$

$0.012001 \pm 0.000053$

$0.0192 \pm 0.00012$

$0.01166 \pm 0.00039$

$0.01146 \pm 0.00044$

$0.01791 \pm 0.0006$

$0.0091 \pm 0.0011$

$0.0193 \pm 0.0014$

$0.01285 \pm 0.00018$

$0.0196 \pm 0.001$

$0.0201 \pm 0.001$

$--$

$0.021109 \pm 0.000031$

$0.01435 \pm 0.00019$

$0.021013 \pm 0.000042$

$0.021223 \pm 0.000047$

$0.01547 \pm 0.00027$
$0.0094595 \pm 0.0000038$

$0.01004 \pm 0.00055$

$0.012685 \pm 0.000056$

$0.02483 \pm 0.00022$

$0.012693 \pm 0.000024$

$0.01152 \pm 0.00017$

$0.011467 \pm 0.000048$

$0.012 \pm 0.00013$

$0.009539 \pm 0.000073$

$0.01141 \pm 0.00036$

$0.011121 \pm 0.000046$

$0.010225 \pm 0.000045$

$0.016389 \pm 0.000099$

$0.01061 \pm 0.00034$

$0.00962 \pm 0.00036$

$0.01558 \pm 0.00052$

$0.0064 \pm 0.00088$

$0.015 \pm 0.0011$

$0.01092 \pm 0.00016$

$0.01615 \pm 0.00087$

$0.01623 \pm 0.00086$

--

$0.018558 \pm 0.000027$

$0.0126 \pm 0.00016$

$0.018512 \pm 0.000037$

$0.018614 \pm 0.000041$

$0.01329 \pm 0.00023$
$0.0078654 \pm 0.0000031$

$0.00758 \pm 0.00045$

$0.010869 \pm 0.000048$

$0.0219 \pm 0.00019$

$0.011018 \pm 0.000021$

$0.01018 \pm 0.00015$

$0.009712 \pm 0.000041$

$0.01015 \pm 0.00011$

$0.007879 \pm 0.000062$

$0.01029 \pm 0.00032$

$0.009653 \pm 0.000039$

$0.008719 \pm 0.000038$

$0.014234 \pm 0.000086$

$0.00892 \pm 0.0003$

$0.00804 \pm 0.00031$

$0.01357 \pm 0.00046$

$0.00575 \pm 0.00087$

$0.0149 \pm 0.0012$

$0.00936 \pm 0.00014$

$0.01428 \pm 0.00077$

$0.01354 \pm 0.00073$

$$
--
$$

$0.016574 \pm 0.000025$

$0.01064 \pm 0.00014$

$0.016573 \pm 0.000033$

$0.016575 \pm 0.000036$

$0.01084 \pm 0.00019$ 
Left adrenal gland

Right breast adipose

Right breast glandular

Left breast adipose

Left breast glandular

Right breast (adipose + glandular)

Left breast (adipose + glandular)

Breast (adipose)

Breast (glandular)

Entire lenses of eye

Sensitive lenses of eye

Right kidney cortex

Right kidney medulla

Right kidney pelvis

Right kidney (cortex + medulla + pelvis)

Left kidney cortex

Left kidney medulla

Left kidney pelvis

Left kidney (cortex + medulla + pelvis)

Right ovary

Left ovary

Pituitary gland

Spinal cord

Ureters

Adipose/residual tissue

Total body

$e_{\mathrm{DW}}$ or $e(\mathrm{mSv} / \mathrm{MBq})$
$0.014 \pm 0.00026$

$0.01095 \pm 0.00029$

$0.01072 \pm 0.00032$

$0.01154 \pm 0.00029$

$0.0103 \pm 0.0003$

$0.01084 \pm 0.00021$

$0.01096 \pm 0.00021$

$0.01095 \pm 0.00021$

$0.01072 \pm 0.00022$

$0.00977 \pm 0.00085$

$0.0151 \pm 0.0024$

$0.013765 \pm 0.000065$

$0.01396 \pm 0.00013$

$0.01397 \pm 0.00027$

$0.013808 \pm 0.000057$

$0.013012 \pm 0.000064$

$0.01352 \pm 0.00013$

$0.01334 \pm 0.00028$

$0.013117 \pm 0.000056$

$0.0194 \pm 0.001$

$0.01318 \pm 0.00012$

$0.0172 \pm 0.0002$

$0.012027 \pm 0.000006$

$0.0130624 \pm 0.0000033$

$0.0199197 \pm 0.0000048$
$0.01203 \pm 0.00022$

$0.0097 \pm 0.00021$

$0.00904 \pm 0.00026$

$0.00949 \pm 0.00021$

$0.00855 \pm 0.00026$

$0.00946 \pm 0.00017$

$0.00913 \pm 0.00016$

$0.0097 \pm 0.00015$

$0.00904 \pm 0.00019$

$0.00785 \pm 0.00072$

$0.0063 \pm 0.0011$

$0.011823 \pm 0.000054$

$0.0121 \pm 0.00011$

$0.01252 \pm 0.00024$

$0.011899 \pm 0.000048$

$0.011093 \pm 0.000054$

$0.01124 \pm 0.00011$

$0.01163 \pm 0.00024$

$0.011139 \pm 0.000047$

$0.01678 \pm 0.00094$

$0.01108 \pm 0.0001$

$0.0149 \pm 0.00017$

$0.0096353 \pm 0.0000039$

$0.0108538 \pm 0.0000026$

$0.0172916 \pm 0.0000037$
$0.01 \pm 0.00019$

$0.00794 \pm 0.00015$

$0.00742 \pm 0.00022$

$0.0081 \pm 0.00015$

$0.00701 \pm 0.00022$

$0.00779 \pm 0.00012$

$0.00778 \pm 0.00012$

$0.00794 \pm 0.0001$

$0.00742 \pm 0.00016$

$0.00858 \pm 0.00078$

$0.0115 \pm 0.0019$

$0.010116 \pm 0.000047$

$0.010542 \pm 0.000094$

$0.01044 \pm 0.0002$

$0.010206 \pm 0.000041$

$0.009369 \pm 0.000046$

$0.009503 \pm 0.00009$

$0.00969 \pm 0.0002$

$0.009405 \pm 0.00004$

$--$

$--$

$0.01457 \pm 0.00083$

$0.009424 \pm 0.000088$

$0.01303 \pm 0.00015$

$0.0078054 \pm 0.0000031$

$0.0090067 \pm 0.0000022$

$0.0150214 \pm 0.0000028$ 
Supplementary Table S7: ${ }^{18} \mathrm{~F}-\mathrm{FDG}$ organ-level absorbed dose coefficients ( $\mathrm{mGy} / \mathrm{MBq}$ ) for the $50^{\text {th }}$ percentile standing height adult male PSPs.

\begin{tabular}{|c|c|c|c|}
\hline \multirow[b]{2}{*}{ Organ/tissue } & \multicolumn{3}{|c|}{ Absorbed dose coefficient (mGy/MBq) } \\
\hline & $\begin{array}{l}\mathrm{H} 50 \text { / W10 male } \\
(177 \mathrm{~cm} / 64.7 \mathrm{~kg})\end{array}$ & $\begin{array}{l}\text { H50 / W50 male } \\
(177 \mathrm{~cm} / 79.3 \mathrm{~kg})\end{array}$ & $\begin{array}{l}\text { H50 / W90 male } \\
(177 \mathrm{~cm} / 99.1 \mathrm{~kg})\end{array}$ \\
\hline Red (active) marrow & $0.011418 \pm 0.000013$ & $0.009979 \pm 0.000011$ & $0.0087713 \pm 0.0000099$ \\
\hline Colon wall & $0.012845 \pm 0.000032$ & $0.011242 \pm 0.000028$ & $0.009499 \pm 0.000023$ \\
\hline Stem cells of colon & $0.01212 \pm 0.00024$ & $0.01041 \pm 0.00021$ & $0.00864 \pm 0.00018$ \\
\hline Right lung + left lung & $0.018779 \pm 0.000028$ & $0.016733 \pm 0.000025$ & $0.015106 \pm 0.000022$ \\
\hline Stomach wall & $0.012878 \pm 0.000051$ & $0.011252 \pm 0.000044$ & $0.009824 \pm 0.000038$ \\
\hline Stem cells of stomach & $0.01046 \pm 0.00028$ & $0.00967 \pm 0.00025$ & $0.00858 \pm 0.00022$ \\
\hline Breast adipose + breast glandular & $0.00966 \pm 0.00013$ & $0.00847 \pm 0.0001$ & $0.00701 \pm 0.000078$ \\
\hline Right ovary + left ovary & -- & -- & -- \\
\hline Testes & $0.01046 \pm 0.00011$ & $0.008788 \pm 0.000092$ & $0.007624 \pm 0.00008$ \\
\hline Urinary bladder wall & $0.05359 \pm 0.00019$ & $0.04784 \pm 0.00016$ & $0.04298 \pm 0.00015$ \\
\hline Urinary bladder basal cells & $0.10104 \pm 0.00091$ & $0.08985 \pm 0.0008$ & $0.07976 \pm 0.00072$ \\
\hline Esophagus wall & $0.01434 \pm 0.0001$ & $0.012617 \pm 0.000087$ & $0.010752 \pm 0.000074$ \\
\hline Esophagus basal cells & $0.01481 \pm 0.00071$ & $0.01219 \pm 0.00063$ & $0.00967 \pm 0.00051$ \\
\hline Liver & $0.018226 \pm 0.000022$ & $0.016422 \pm 0.00002$ & $0.014934 \pm 0.000018$ \\
\hline Thyroid & $0.01003 \pm 0.00013$ & $0.00875 \pm 0.00012$ & $0.00774 \pm 0.0001$ \\
\hline $\begin{array}{l}\text { 50um endosteal region (endosteal } \\
\text { cells) }\end{array}$ & $0.009515 \pm 0.00001$ & $0.0079932 \pm 0.0000089$ & $0.0068931 \pm 0.0000077$ \\
\hline Brain & $0.032571 \pm 0.000039$ & $0.031604 \pm 0.000038$ & $0.030585 \pm 0.000037$ \\
\hline Salivary glands & $0.009688 \pm 0.000069$ & $0.008232 \pm 0.00006$ & $0.00697 \pm 0.000052$ \\
\hline Skin & $0.0079062 \pm 0.0000092$ & $0.0064697 \pm 0.0000075$ & $0.0053954 \pm 0.0000068$ \\
\hline Basal cells of skin & $0.006194 \pm 0.000025$ & $0.005229 \pm 0.000022$ & $0.004347 \pm 0.000019$ \\
\hline Right adrenal + left adrenal & $0.01345 \pm 0.00017$ & $0.01151 \pm 0.00014$ & $0.01027 \pm 0.00013$ \\
\hline ET region & $0.010144 \pm 0.000095$ & $0.00873 \pm 0.000085$ & $0.007572 \pm 0.000075$ \\
\hline Gallbladder wall & $0.01303 \pm 0.0002$ & $0.01166 \pm 0.00017$ & $0.0103 \pm 0.00015$ \\
\hline Heart wall & $0.057359 \pm 0.000092$ & $0.050815 \pm 0.000081$ & $0.04553 \pm 0.000073$ \\
\hline Right kidney + left kidney & $0.011979 \pm 0.000035$ & $0.010421 \pm 0.00003$ & $0.009009 \pm 0.000026$ \\
\hline Systemic lymph nodes & $0.014063 \pm 0.000053$ & $0.012327 \pm 0.000046$ & $0.010868 \pm 0.00004$ \\
\hline
\end{tabular}


Muscle

Oral mucosa

Pancreas

Prostate

Small intestine wall

Stem cells of small intestine

Spleen

Thymus

Uterus/cervix

Tongue

Tonsils

Right colon wall (ascending + right transverse)

Left colon wall (left transverse + descending)

Rectosigmoid colon wall (sigmoid + rectum)

Stem cells of right colon (ascending + right transverse)

Stem cells of left colon (left transverse + descending)

Stem cells of rectosigmoid colon (sigmoid + rectum)

Basal cells of anterior nasal passages

Basal cells of posterior nasal passages + pharynx

Extrathoracic lymph nodes

Bronchial basal cells

Bronchial secretory cells

Bronchiolar secretory cells

Alveolar-interstitium

Thoracic lymph nodes

Right lung lobe

Left lung lobe

Right adrenal gland

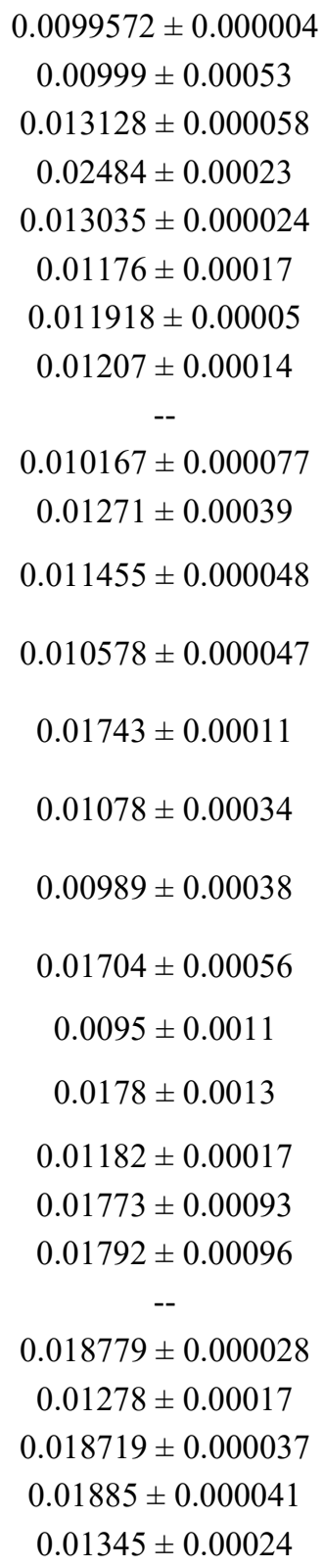

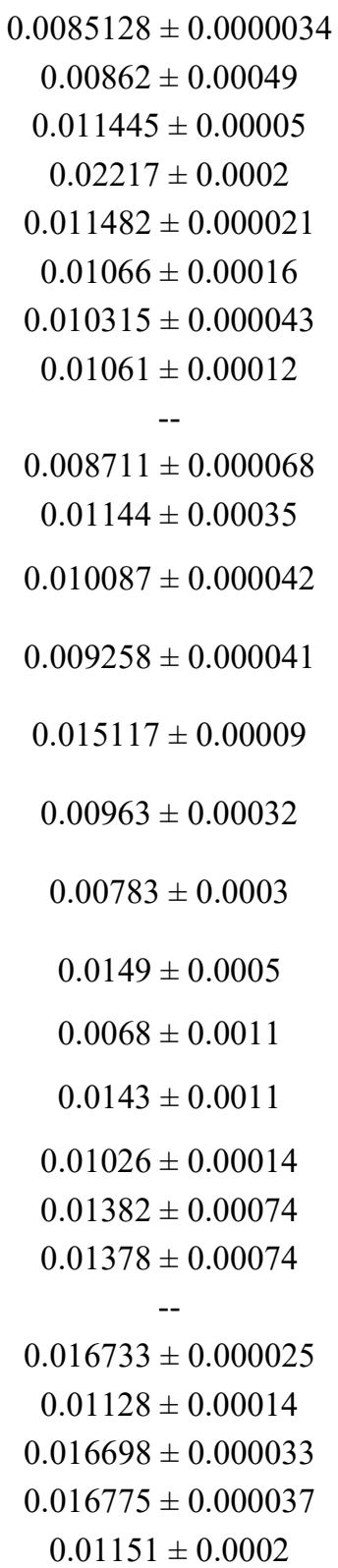

\author{
$0.0072307 \pm 0.0000029$ \\ $0.00721 \pm 0.00042$ \\ $0.009859 \pm 0.000043$ \\ $0.02 \pm 0.00018$ \\ $0.009989 \pm 0.000019$ \\ $0.00928 \pm 0.00014$ \\ $0.008893 \pm 0.000037$ \\ $0.00929 \pm 0.0001$ \\ $0.007206 \pm 0.000058$ \\ $0.00926 \pm 0.0003$ \\ $0.008719 \pm 0.000036$ \\ $0.00786 \pm 0.000034$ \\ $0.013245 \pm 0.000079$ \\ $0.00806 \pm 0.00027$ \\ $0.00684 \pm 0.00027$ \\ $0.01182 \pm 0.0004$ \\ $0.00519 \pm 0.00076$ \\ $0.01258 \pm 0.00097$ \\ $0.00884 \pm 0.00013$ \\ $0.01284 \pm 0.00071$ \\ $0.0128 \pm 0.00069$ \\ $--$ \\ $0.015106 \pm 0.000022$ \\ $0.01004 \pm 0.00013$ \\ $0.015101 \pm 0.00003$ \\ $0.015112 \pm 0.000032$ \\ $0.01027 \pm 0.00018$
}


Left adrenal gland

Right breast adipose

Right breast glandular

Left breast adipose

Left breast glandular

Right breast (adipose + glandular)

Left breast (adipose + glandular)

Breast (adipose)

Breast (glandular)

Entire lenses of eye

Sensitive lenses of eye

Right kidney cortex

Right kidney medulla

Right kidney pelvis

Right kidney (cortex + medulla + pelvis)

Left kidney cortex

Left kidney medulla

Left kidney pelvis

Left kidney (cortex + medulla + pelvis)

Right ovary

Left ovary

Pituitary gland

Spinal cord

Ureters

Adipose/residual tissue

Total body

$e_{\mathrm{DW}}$ or $e(\mathrm{mSv} / \mathrm{MBq})$
$0.01236 \pm 0.00023$

$0.00992 \pm 0.00024$

$0.00931 \pm 0.00027$

$0.01036 \pm 0.00024$

$0.00947 \pm 0.00027$

$0.00966 \pm 0.00018$

$0.00997 \pm 0.00018$

$0.00992 \pm 0.00017$

$0.00931 \pm 0.00019$

$0.00872 \pm 0.0008$

$0.0057 \pm 0.0012$

$0.012221 \pm 0.000057$

$0.01251 \pm 0.00011$

$0.01232 \pm 0.00024$

$0.012277 \pm 0.00005$

$0.011533 \pm 0.000057$

$0.0116 \pm 0.00011$

$0.01167 \pm 0.00024$

$0.011549 \pm 0.000049$

$0.01857 \pm 0.001$

$0.01169 \pm 0.00011$

$0.01522 \pm 0.00018$

$0.010387 \pm 0.0000052$

$0.0114761 \pm 0.0000029$

$0.0176694 \pm 0.0000037$
$0.01036 \pm 0.0002$

$0.00893 \pm 0.00019$

$0.00769 \pm 0.00023$

$0.00894 \pm 0.00019$

$0.00713 \pm 0.00022$

$0.00847 \pm 0.00015$

$0.00827 \pm 0.00014$

$0.00893 \pm 0.00013$

$0.00769 \pm 0.00016$

$0.00855 \pm 0.00076$

$0.0085 \pm 0.0016$

$0.010633 \pm 0.000049$

$0.010988 \pm 0.000098$

$0.01109 \pm 0.00021$

$0.010716 \pm 0.000043$

$0.009948 \pm 0.000049$

$0.010177 \pm 0.000096$

$0.0104 \pm 0.00021$

$0.010007 \pm 0.000043$

$--$

$-$

$0.01595 \pm 0.00089$

$0.010053 \pm 0.000093$

$0.01332 \pm 0.00015$

$0.0086155 \pm 0.0000034$

$0.0100548 \pm 0.0000027$

$0.0155005 \pm 0.0000029$
$0.00921 \pm 0.00017$

$0.00724 \pm 0.00013$

$0.00645 \pm 0.00019$

$0.00709 \pm 0.00013$

$0.00624 \pm 0.00019$

$0.00701 \pm 0.00011$

$0.00684 \pm 0.00011$

$0.007244 \pm 0.000094$

$0.00645 \pm 0.00014$

$0.00665 \pm 0.00064$

$0.0058 \pm 0.0012$

$0.009221 \pm 0.000042$

$0.00956 \pm 0.000085$

$0.00952 \pm 0.00018$

$0.009295 \pm 0.000037$

$0.008591 \pm 0.000042$

$0.008565 \pm 0.000081$

$0.00874 \pm 0.00018$

$0.008591 \pm 0.000037$

$$
--
$$$$
\text { -- }
$$

$0.01588 \pm 0.00084$

$0.008673 \pm 0.000081$

$0.01185 \pm 0.00013$

$0.0071031 \pm 0.0000028$

$0.0082201 \pm 0.000002$

$0.0136077 \pm 0.0000023$ 
Supplementary Table S8: ${ }^{18} \mathrm{~F}-\mathrm{FDG}$ organ-level absorbed dose coefficients ( $\mathrm{mGy} / \mathrm{MBq}$ ) for the $90^{\text {th }}$ percentile standing height adult male PSPs.

\begin{tabular}{|c|c|c|c|}
\hline \multirow[b]{2}{*}{ Organ/tissue } & \multicolumn{3}{|c|}{ Absorbed dose coefficient (mGy/MBq) } \\
\hline & $\begin{array}{l}\text { H90 / W10 male } \\
(186 \mathrm{~cm} / 74.2 \mathrm{~kg})\end{array}$ & $\begin{array}{l}\text { H90 / W50 male } \\
(186 \mathrm{~cm} / 88.7 \mathrm{~kg})\end{array}$ & $\begin{array}{l}\text { H90 / W90 male } \\
(186 \mathrm{~cm} / 108.4 \mathrm{~kg})\end{array}$ \\
\hline Red (active) marrow & $0.010275 \pm 0.000012$ & $0.009148 \pm 0.00001$ & $0.0080557 \pm 0.0000091$ \\
\hline Colon wall & $0.011337 \pm 0.000028$ & $0.010188 \pm 0.000025$ & $0.009039 \pm 0.000022$ \\
\hline Stem cells of colon & $0.01078 \pm 0.00021$ & $0.00938 \pm 0.00019$ & $0.00871 \pm 0.00018$ \\
\hline Right lung + left lung & $0.016896 \pm 0.000025$ & $0.015254 \pm 0.000022$ & $0.013866 \pm 0.00002$ \\
\hline Stomach wall & $0.011584 \pm 0.000045$ & $0.010266 \pm 0.00004$ & $0.009161 \pm 0.000035$ \\
\hline Stem cells of stomach & $0.00987 \pm 0.00026$ & $0.00895 \pm 0.00023$ & $0.00818 \pm 0.00021$ \\
\hline Breast adipose + breast glandular & $0.00855 \pm 0.00011$ & $0.007463 \pm 0.000089$ & $0.006578 \pm 0.000072$ \\
\hline Right ovary + left ovary & -- & -- & -- \\
\hline Testes & $0.009482 \pm 0.000097$ & $0.008087 \pm 0.000084$ & $0.007281 \pm 0.000075$ \\
\hline Urinary bladder wall & $0.04822 \pm 0.00016$ & $0.04359 \pm 0.00015$ & $0.03967 \pm 0.00013$ \\
\hline Urinary bladder basal cells & $0.08945 \pm 0.00081$ & $0.08046 \pm 0.00072$ & $0.07213 \pm 0.00066$ \\
\hline Esophagus wall & $0.012929 \pm 0.000089$ & $0.011432 \pm 0.000078$ & $0.0099 \pm 0.000068$ \\
\hline Esophagus basal cells & $0.01292 \pm 0.00064$ & $0.0114 \pm 0.00057$ & $0.0098 \pm 0.0005$ \\
\hline Liver & $0.016395 \pm 0.00002$ & $0.014999 \pm 0.000018$ & $0.013796 \pm 0.000017$ \\
\hline Thyroid & $0.00938 \pm 0.00012$ & $0.00805 \pm 0.0001$ & $0.00679 \pm 0.00009$ \\
\hline $\begin{array}{l}\text { 50um endosteal region (endosteal } \\
\text { cells) }\end{array}$ & $0.0082778 \pm 0.0000092$ & $0.0073133 \pm 0.000008$ & $0.006365 \pm 0.0000071$ \\
\hline Brain & $0.031262 \pm 0.000038$ & $0.030414 \pm 0.000036$ & $0.029442 \pm 0.000035$ \\
\hline Salivary glands & $0.008616 \pm 0.000062$ & $0.007558 \pm 0.000055$ & $0.006411 \pm 0.000049$ \\
\hline Skin & $0.0068933 \pm 0.000008$ & $0.0058728 \pm 0.0000068$ & $0.0049031 \pm 0.0000061$ \\
\hline Basal cells of skin & $0.005497 \pm 0.000023$ & $0.004761 \pm 0.00002$ & $0.004001 \pm 0.000018$ \\
\hline Right adrenal + left adrenal & $0.01177 \pm 0.00015$ & $0.01089 \pm 0.00013$ & $0.0092 \pm 0.00011$ \\
\hline ET region & $0.009213 \pm 0.000087$ & $0.008058 \pm 0.000078$ & $0.006954 \pm 0.00007$ \\
\hline Gallbladder wall & $0.0118 \pm 0.00018$ & $0.01046 \pm 0.00016$ & $0.00963 \pm 0.00014$ \\
\hline Heart wall & $0.051223 \pm 0.000082$ & $0.046046 \pm 0.000074$ & $0.041662 \pm 0.000062$ \\
\hline Right kidney + left kidney & $0.010668 \pm 0.000031$ & $0.009477 \pm 0.000027$ & $0.00819 \pm 0.000024$ \\
\hline Systemic lymph nodes & $0.012661 \pm 0.000047$ & $0.011409 \pm 0.000042$ & $0.010282 \pm 0.000037$ \\
\hline
\end{tabular}


Muscle

Oral mucosa

Pancreas

Prostate

Small intestine wall

Stem cells of small intestine

Spleen

Thymus

Uterus/cervix

Tongue

Tonsils

Right colon wall (ascending + right transverse)

Left colon wall (left transverse + descending)

Rectosigmoid colon wall (sigmoid + rectum)

Stem cells of right colon (ascending + right transverse)

Stem cells of left colon (left transverse + descending)

Stem cells of rectosigmoid colon (sigmoid + rectum)

Basal cells of anterior nasal passages

Basal cells of posterior nasal passages + pharynx

Extrathoracic lymph nodes

Bronchial basal cells

Bronchial secretory cells

Bronchiolar secretory cells

Alveolar-interstitium

Thoracic lymph nodes

Right lung lobe

Left lung lobe

Right adrenal gland
$0.0088422+0.0000035$

$0.00843 \pm 0.00046$

$0.011748 \pm 0.000052$

$0.02236 \pm 0.0002$

$0.011573 \pm 0.000022$

$0.01053 \pm 0.00016$

$0.010773 \pm 0.000044$

$0.01092 \pm 0.00012$

$0.008992 \pm 0.000069$

$0.01133 \pm 0.00035$

$0.010108 \pm 0.000042$

$0.00939 \pm 0.000041$

$0.01528 \pm 0.000091$

$0.00974 \pm 0.00032$

$0.00934 \pm 0.00035$

$0.01425 \pm 0.00048$

$0.0078 \pm 0.0011$

$0.015 \pm 0.0011$

$0.01045 \pm 0.00015$

$0.01587 \pm 0.00081$

$0.01553 \pm 0.00082$

$-$

$0.016896 \pm 0.000025$

$0.01164 \pm 0.00015$

$0.016842 \pm 0.000034$

$0.016961 \pm 0.000037$

$0.01177 \pm 0.00021$
$0.0077247 \pm 0.0000031$

$0.00756 \pm 0.00041$

$0.010397 \pm 0.000045$

$0.02022 \pm 0.00018$

$0.01041 \pm 0.000019$

$0.00974 \pm 0.00014$

$0.009362 \pm 0.000038$

$0.00973 \pm 0.00011$

$0.007778 \pm 0.000061$

$0.01028 \pm 0.00032$

$0.009102 \pm 0.000037$

$0.008267 \pm 0.000036$

$0.01382 \pm 0.000081$

$0.00862 \pm 0.00029$

$0.00786 \pm 0.0003$

$0.0125 \pm 0.00043$

$0.0082 \pm 0.001$

$0.0147 \pm 0.0011$

$0.00929 \pm 0.00013$

$0.01463 \pm 0.00075$

$0.01384 \pm 0.00074$

$$
--
$$

$0.015254 \pm 0.000022$

$0.01029 \pm 0.00013$

$0.015216 \pm 0.00003$

$0.0153 \pm 0.000032$

$0.01089 \pm 0.00019$
$0.0066393 \pm 0.0000027$

$0.00647 \pm 0.00037$

$0.00919 \pm 0.00004$

$0.01869 \pm 0.00016$

$0.009327 \pm 0.000017$

$0.00871 \pm 0.00013$

$0.00806 \pm 0.000034$

$0.00844 \pm 0.000095$

$0.006726 \pm 0.000054$ $0.00934 \pm 0.0003$

$0.00808 \pm 0.000033$

$0.007381 \pm 0.000032$

$0.01246 \pm 0.000072$

$0.00808 \pm 0.00027$

$0.00713 \pm 0.00027$

$0.01172 \pm 0.00039$

$0.00546 \pm 0.00079$

$0.0128 \pm 0.001$

$0.00807 \pm 0.00012$

$0.01218 \pm 0.00067$

$0.01256 \pm 0.00067$

--

$0.013866 \pm 0.00002$

$0.00886 \pm 0.00011$

$0.013877 \pm 0.000028$

$0.013853 \pm 0.000029$

$0.0092 \pm 0.00016$ 
Left adrenal gland

Right breast adipose

Right breast glandular

Left breast adipose

Left breast glandular

Right breast (adipose + glandular)

Left breast (adipose + glandular)

Breast (adipose)

Breast (glandular)

Entire lenses of eye

Sensitive lenses of eye

Right kidney cortex

Right kidney medulla

Right kidney pelvis

Right kidney (cortex + medulla + pelvis)

Left kidney cortex

Left kidney medulla

Left kidney pelvis

Left kidney (cortex + medulla + pelvis)

Right ovary

Left ovary

Pituitary gland

Spinal cord

Ureters

Adipose/residual tissue

Total body

$e_{\mathrm{DW}}$ or $e(\mathrm{mSv} / \mathrm{MBq})$
$0.01046 \pm 0.00019$

$0.00897 \pm 0.00021$

$0.00798 \pm 0.00023$

$0.00933 \pm 0.00022$

$0.00881 \pm 0.00025$

$0.00855 \pm 0.00016$

$0.00911 \pm 0.00016$

$0.00897 \pm 0.00015$

$0.00798 \pm 0.00016$

$0.00933 \pm 0.00084$

$0.0081 \pm 0.0014$

$0.010856 \pm 0.00005$

$0.01128 \pm 0.0001$

$0.011 \pm 0.00021$

$0.010939 \pm 0.000044$

$0.010254 \pm 0.00005$

$0.010231 \pm 0.000096$

$0.01055 \pm 0.00021$

$0.010261 \pm 0.000044$

$0.01703 \pm 0.00092$

$0.01059 \pm 0.000096$

$0.01363 \pm 0.00016$

$0.0092199 \pm 0.0000046$

$0.0102291 \pm 0.0000026$

$0.0158446 \pm 0.0000029$
$0.00972 \pm 0.00018$

$0.00781 \pm 0.00016$

$0.00686 \pm 0.0002$

$0.00784 \pm 0.00016$

$0.00711 \pm 0.0002$

$0.00746 \pm 0.00013$

$0.00758 \pm 0.00013$

$0.00781 \pm 0.00011$

$0.00686 \pm 0.00014$

$0.00797 \pm 0.00076$

$0.0101 \pm 0.002$

$0.009698 \pm 0.000045$

$0.009902 \pm 0.000088$

$0.00999 \pm 0.00019$

$0.009746 \pm 0.000039$

$0.009032 \pm 0.000043$

$0.009164 \pm 0.000086$

$0.0096 \pm 0.00019$

$0.009077 \pm 0.000038$

$--$

$--$

$0.01524 \pm 0.00084$

$0.009073 \pm 0.000083$

$0.01232 \pm 0.00014$

$0.0078156 \pm 0.0000031$

$0.0088606 \pm 0.0000021$

$0.0141068 \pm 0.0000024$
$0.00813 \pm 0.00015$

$0.00676 \pm 0.00012$

$0.00615 \pm 0.00018$

$0.00671 \pm 0.00012$

$0.00622 \pm 0.00018$

$0.00658 \pm 0.0001$

$0.00657 \pm 0.0001$

$0.006758 \pm 0.000087$

$0.00615 \pm 0.00013$

$0.00513 \pm 0.00057$

$0.00374 \pm 0.00099$

$0.008381 \pm 0.000039$

$0.008562 \pm 0.000076$

$0.00861 \pm 0.00016$

$0.008423 \pm 0.000034$

$0.007798 \pm 0.000038$

$0.007987 \pm 0.000075$

$0.00806 \pm 0.00016$

$0.007842 \pm 0.000033$

$--$

$0.01487 \pm 0.00081$

$0.007932 \pm 0.000074$

$0.01085 \pm 0.00012$

$0.0066291 \pm 0.0000027$

$0.0075807 \pm 0.0000018$

$0.0127004 \pm 0.0000019$ 